\title{
Rheological Evaluation of Simulated Neutralized Current Acid Waste
}

\author{
C. L. Fow \\ D. McCarthy \\ G. T. Thornton
}

June 1986

Prepared for the U.S. Department of Energy under Contract DE-AC06-76RLO 1830

Pacific Northwest Laboratory Operated for the U.S. Department of Energy by Battelle Memorial Institute 


\title{
DISCLAIMER
}

This report was prepared as an account of work sponsored by an agency of the United States Government. Neither the United States Government nor any agency thereof, nor any of their employees, makes any warranty, express or implied, or assumes any legal liability or responsibility for the accuracy, completeness, or usefulness of any information, apparatus, product, or process disclosed, or represents that its use would not infringe privately owned rights. Reference herein to any specific commercial product, process, or service by trade name, trademark, manufacturer, or otherwise, does not necessarily constitute or imply its endorsement, recommendation, or favoring by the United States Government or any agency thereof. The views and opinions of authors expressed herein do not necessarily state or reflect those of the United States Government or any agency thereof.

\author{
PACIFIC NORTHWEST LABORATORY \\ operated by \\ BATTELLE \\ for the \\ UNITED STATES DEPARTMENT OF ENERGY \\ under Contract DE-AC06-76RLO 1830
}

\begin{tabular}{|c|c|}
\hline \multirow{2}{*}{\multicolumn{2}{|c|}{ Printed in the United States of America }} \\
\hline & \\
\hline \multicolumn{2}{|c|}{$\begin{array}{l}\text { Available from } \\
\text { National Technical Information Service }\end{array}$} \\
\hline \multirow{3}{*}{\multicolumn{2}{|c|}{$\begin{array}{c}\text { United States Department of Commerce } \\
5285 \text { Port Royal Road } \\
\text { Springfield, Virginia } 22161\end{array}$}} \\
\hline & \\
\hline & \\
\hline \multirow{2}{*}{\multicolumn{2}{|c|}{$\begin{array}{l}\text { NTIS Price Codes } \\
\text { Microfiche A01 }\end{array}$}} \\
\hline & \\
\hline \multicolumn{2}{|c|}{ Printed Copy } \\
\hline & Price \\
\hline Pages & Codes \\
\hline $001-025$ & A02 \\
\hline 026-050 & $\mathrm{A} 03$ \\
\hline 051-075 & A04 \\
\hline $076-100$ & A05 \\
\hline $101-125$ & $A 06$ \\
\hline $126-150$ & A07 \\
\hline $151-175$ & $A 0 B$ \\
\hline $176-200$ & $A 09$ \\
\hline $201-225$ & A010 \\
\hline $226-250$ & A011 \\
\hline 251-275 & A012 \\
\hline $276-300$ & $A 013$ \\
\hline
\end{tabular}


RHEOLOGICAL EVALUATION OF SIMULATED

NEUTRALIZED CURRENT ACID WASTE
C. L. Fow
D. Mclarthy
G. T. Thornton

June 1986

Prepared for

the U.S. Department of Energy

under Contract DE-AC06-76RLO 1830

Pacific Northwest Laboratory

Richland, Washington 99352 



\section{SUMMARY}

At the Hanford Plutonium and Uranium Extraction Plant, in Richland, Washington, plutonium and uranium products are recovered from irradiated fuel by a solvent extraction process. A byproduct of this process is an aqueous waste stream that contains fission products. This waste stream, called current acid waste, is chemically neutralized and stored in double shell tanks (DSTs) on the Hanford Site. This neutralized current acid waste (NCAW) will be transported by pipe to B-Plant, a processing plant on the Hanford Site. After being processed, the NCAW will be permanently disposed of .

Retrieving and transporting the NCAW is complicated by the fact that 50 to 60 inches of solids may have settled on the bottom of the DSTs. These settled particles are radiologically and thermally hot (up to $85^{\circ} \mathrm{C}$ ).

To help assure the successful retrieval and transportation of NCAW slurry to B-Plant, researchers at Pacific Northwest Laboratory evaluated the rheological and transport properties of NCAW slurry. This evaluation had two phases. First, researchers conducted lab rheological evaluations of simulated NCAW. The results of these evaluations were then correlated with classical rheological models and scaled up to predict the performance that is likely to occur in the full-scale system. This scale-up procedure has already been successfully used to predict the critical transport properties of a slurry with rheological properties similar to those displayed by NCAW (MCCarthy, Chan and Lokken 1985).

The NCAW in the tank will either be retrieved as is, i.e., no change in the concentration presently in the tank, or will be slightly concentrated before retrieval. Sluicing may be required to retrieve the solids. For this report, three concentrations of simulated NCAW were evaluated that would simulate the different retrieval options: 1) NCAW in the concentration that is presently in the tank, 2) a slightly concentrated NCAW, called NCAW5.5, and 3) equal parts of NCAW settled solids and water (simulating the sluicing stage), called NCANl:1.

The physical and rheological properties of three samples of each concentration at 25 and $100^{\circ} \mathrm{C}$ were evaluated in the laboratory. The properties 
displayed by NCAW and NCAW5.5 at 25 and $100^{\circ} \mathrm{C}$ allowed it to be classified as a pseudoplastic non-Newtonian fluid. NCAW1:1 at 25 and $100^{\circ} \mathrm{C}$ displayed properties of a yield-pseudoplastic non-Newtonian fluid. The classical non-Newtonian models for pseudoplastic and yield-pseudoplastic fluids were used with the laboratory data to predict the full-scale pump-pipe network parameters.

The full-scale pump-pipe network must transport NCAW slurries at velocities that prevent the deposition of solids in the transfer lines. Laboratory critical velocity estimates were scaled up to predict full-scale performance. These estimates indicate that a critical transport velocity of 0.65 feet per second (fps) will be required to suspend NCAW and NCAW5.5 in the full-scale system. The critical transport velocity required to suspend NCAW1:1 in the full-scale system is $1.55 \mathrm{fps}$. These velocities are below the design velocity in the full-scale system (2.1 fps; $50 \mathrm{gpm}$ ) and should prevent solids deposition in transfer lines during normal operations.

The pump used to transport NCAW slurries must be sized to overcome pressure losses that will result as the slurries flow through the full-scale pipe network. Laboratory data were scaled up to provide estimates of these pressure losses. These estimated data are summarized in Table 1. These estimates assume that each slurry will be pumped through a 3-in., schedule 40, smooth, carbon steel pipe with an equivalent length of 9100 feet. These assumptions reflect the current design parameters for the full-scale system. When information about the pipe roughness of the actual full-scale pipe network become available, these predictions of pressure drop must be adjusted.

The current Rockwell Hanford Operations (Rockwell) design for the fullscale pump-pipe system specified that one pipe volume of water be used for flushing, and that water be delivered at a rate of $75 \mathrm{gpm}(3.3 \mathrm{fps}$ ). A

TABLE 1. Predictions of Ful1-Scale Pressure Orop (psi)

\begin{tabular}{|c|c|c|c|c|c|c|}
\hline \multirow{2}{*}{$\begin{array}{l}\text { Flow } \\
\text { Rate }\end{array}$} & \multicolumn{2}{|c|}{ NCAW } & \multicolumn{2}{|c|}{ NCA } & \multicolumn{2}{|c|}{ NCAW $1: 1$} \\
\hline & $25^{\circ} \mathrm{C}$ & $100^{\circ} \mathrm{C}$ & $25^{\circ} \mathrm{C}$ & $100^{\circ} \mathrm{C}$ & $25^{\circ} \mathrm{C}$ & $100^{\circ} \mathrm{C}$ \\
\hline $50 \mathrm{gpm}$ & 40 & 28 & 41 & 26 & 38 & 36 \\
\hline $75 \mathrm{gpm}$ & 77 & 56 & 80 & 60 & 72 & 60 \\
\hline
\end{tabular}


resuspension velocity of 3.3 fps is approximately 5, 5, and 2 times the fullscale velocities predicted as the laminar-turbulent transition velocities for NCAW, and NCAW5.5 and NCAW1:1, respectively, at $25^{\circ} \mathrm{C}$.

The degree of resuspension achieved during flushing will be a function of the pressure gradient applied to the settled solids, the steady-state fluid velocity achieved in the pipe, and the amount of flush water delivered during the flush. The pressure gradient necessary to resuspend settled NCAW must be established during pilot-scale tests using a pump-pipe test loop. These tests were beyond the scope of this program.

A series of pilot-scale resuspension tests with Neutralized Cladding Removal Waste (NCRW) was completed recently (McCarthy, Chan, and Lokken 1985). The NCRW slurry exhibited properties that were similar to those exhibited by the NCAW slurries. Some of these properties are summarized in Table 2. Table 6.6 shows that the predicted pressure drop for NCAW1:1 is 1ower than for NCAW5.5 even though the viscosity of NCAWl:1 is higher. For Newtonian and nonNewtonian fluids, the pressure drop is a function of the friction factor. For Newtonian fluids, the friction factor is a function of the Reynolds number and the relative roughness of the pipe. For non-Newtonian fluids, the relationship is more complex. There is not a direct correlation between viscosity and pressure drop. Therefore, as seen in Table 6.6, the fact that NCAW1:1 has a higher viscosity than the other NCAN slurries, yet a lower pressure drop, is not unexpected.

TABLE 2. Comparison of NCAW and NCRW Slurry Properties at $25^{\circ} \mathrm{C}$

\begin{tabular}{|c|c|c|c|c|}
\hline Property & NCRW & NCAW & NCAW5.5 & NCAW : 1 \\
\hline Viscosity at $50 \mathrm{sec}^{-1}, \mathrm{cP}$ & 4 & 8 & 8 & 18 \\
\hline$V_{c}-f u l l-s c a l e$, fps & $0.3-0.4$ & $0.5-0.6$ & $0.5-0.6$ & $1.2-1.5$ \\
\hline $\begin{array}{l}\Delta P \text { for } 9100 \mathrm{ft}, \mathrm{psi} \\
\text { at } 2.1 \mathrm{fps}\end{array}$ & $31-36$ & 41 & 41 & 38 \\
\hline
\end{tabular}


During the NCRW pilot-scale tests, the pressure gradient applied during resuspension equaled about 1.3 times the normal pressure drop associated with a flow velocity of $3.3 \mathrm{fps}$. If this criterion is applied to the full-scale NCAW system, a pressure drop of approximately 100, 104, and 94 psig would result during flushing of NCAW, NCAW5.5, and NCAW 1:1, respectively. These predictions of full-scale line flushing pressure drop requirements are estimates. Actual requirements must be established during pilot-scale tests. 


\section{CONTENTS}

SUMMARY

$i \mathrm{i}$

1.D INTRODUCTION ANO OBJECTIVES $\ldots \ldots \ldots \ldots \ldots \ldots \ldots \ldots \ldots \ldots \ldots \ldots \ldots \ldots . . \ldots$

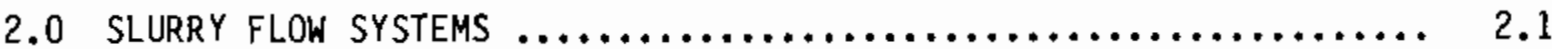

2.1 CLASSIFICATION OF SLURRIES $\ldots \ldots \ldots \ldots \ldots \ldots \ldots \ldots \ldots \ldots \ldots \ldots \ldots \ldots \ldots \ldots \ldots$

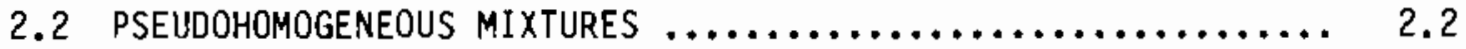

2.2.1 Time-Independent Non-Newtonian Fluids ........... 2.3

2.2.2 Time-Dependent Non-Newtonian Fluids ............. $2.5 \ldots$

2.2 .3 Viscoelastic Fluids $\ldots \ldots \ldots \ldots \ldots \ldots \ldots \ldots \ldots \ldots \ldots . \ldots \ldots$

2.3 HETEROGENEOUS FlOW SYSTEMS $\ldots \ldots \ldots \ldots \ldots \ldots \ldots \ldots \ldots \ldots \ldots \ldots . . \ldots$

2.3.1 Heterogeneous Slurry-Flow Patterns ............. 2.7

3.D PREPARATION OF SIMULATED CURRENT ACID WASTE $\ldots \ldots \ldots \ldots \ldots \ldots \ldots \ldots . . .$.

3.1 LABORATORY PREPARATION PROCEDURES $\ldots \ldots \ldots \ldots \ldots \ldots \ldots \ldots \ldots \ldots . . .1$

4.0 LABORATORY RHEOLOGICAL EVALUATIONS $\ldots \ldots \ldots \ldots \ldots \ldots \ldots \ldots \ldots \ldots \ldots . \ldots \ldots$

4.1 EXPERIMENTAL EqUIPMENT AND PROCEDURES $\ldots \ldots \ldots \ldots \ldots \ldots \ldots \ldots .4 .1$

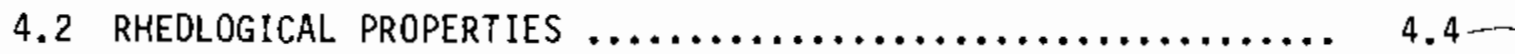

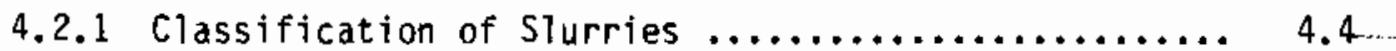

4.2 .2 Viscosity of NCAW Slurries $\ldots \ldots \ldots \ldots \ldots \ldots \ldots \ldots \ldots . \ldots \ldots \ldots$

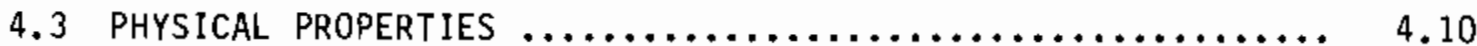

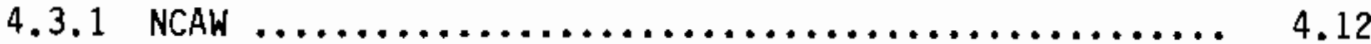

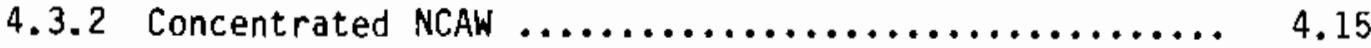

4.3 .3 NCAW $1: 1 \ldots \ldots \ldots \ldots \ldots \ldots \ldots \ldots \ldots \ldots \ldots \ldots \ldots \ldots \ldots . . \ldots \ldots$

5.0 RHEOLOGICAL MODELS FOR FLOW IN PIPES $\ldots \ldots \ldots \ldots \ldots \ldots \ldots \ldots \ldots \ldots . \ldots \ldots$

5.1 PSEUDOPLASTIC FLUIDS $\ldots \ldots \ldots \ldots \ldots \ldots \ldots \ldots \ldots \ldots \ldots \ldots \ldots \ldots \ldots \ldots \ldots \ldots$

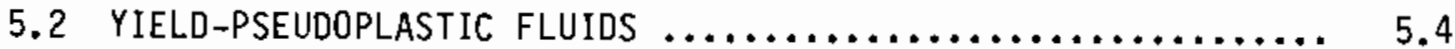


6.0 DESIGN REQUIREMENTS FOR THE FULL-SCALE SYSTEM $\ldots \ldots \ldots \ldots \ldots \ldots, 6.1$

6.1 SCALE-UP OF LABORATORY RHEOLOGICAL DATA $\ldots \ldots \ldots \ldots \ldots \ldots . \ldots .1$

6.1 .1 Pseudoplastic Model $\ldots \ldots \ldots \ldots \ldots \ldots \ldots \ldots \ldots \ldots . .6 .2$

6.1 .2 Yield-Pseudoplastic Model $\ldots \ldots \ldots \ldots \ldots \ldots \ldots \ldots \ldots .6 .2$

6.2 PRESSURE DROP EXPECTED IN THE FULL-SCALE SYSTEM $\ldots \ldots \ldots \ldots, 6.3$

6.2 .1 NCAW, NCAW5.5 and NCAW1:1 Slurries..$\ldots \ldots \ldots \ldots \ldots .6 .4$

6.3 FULL-SCALE LINE-FLUSHING REQUIREMENTS $\ldots \ldots \ldots \ldots \ldots \ldots \ldots \ldots \ldots \ldots \ldots$

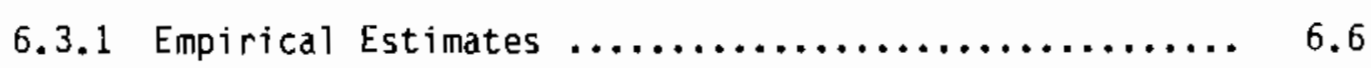

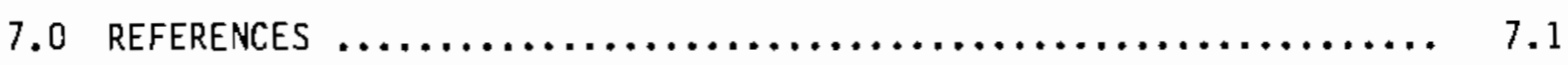




\section{FIGURES}

2.1 Classification of Complex Mixtures $\ldots \ldots \ldots \ldots \ldots \ldots \ldots \ldots \ldots, 2.1$

2.2 Rheograms for Time-Independent Non-Newtonian Fluids ......... 2.3

2.3 Rheograms for Thixotropic and Rheopectic

Non-Newtonian Fluids $\ldots \ldots \ldots \ldots \ldots \ldots \ldots \ldots \ldots \ldots \ldots \ldots \ldots . \ldots \ldots$

2.4 Flow Curve for Heterogeneous Slurries $\ldots \ldots \ldots \ldots \ldots \ldots \ldots \ldots \ldots \ldots$

2.5 Heterogeneous Slurry Flow Patterns $\ldots \ldots \ldots \ldots \ldots \ldots \ldots \ldots \ldots \ldots . . . . . \ldots$

2.6 Heterogeneous Slurry Flow Patterns; Particle Diameter and Velocity Effects .................................... 2.10

4.1 Schematic of a Haake Rotovisco Viscometer ............... 4.2

4.2 Flow Curve for a Yield-Pseudoplastic Material ............. 4.3

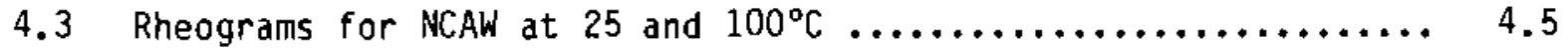

4.4 Rheograms for NCAw5.5 at 25 and $100^{\circ} \mathrm{C} \ldots \ldots \ldots \ldots \ldots \ldots \ldots \ldots \ldots$

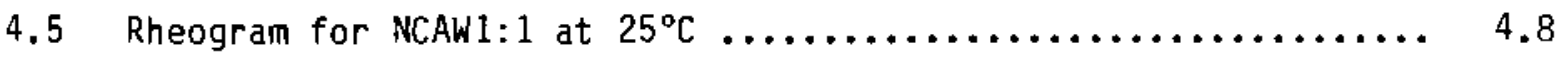

4.6 Rheogram for NCAW $1: 1$ at $100^{\circ} \mathrm{C} \ldots \ldots \ldots \ldots \ldots \ldots \ldots \ldots \ldots \ldots \ldots \ldots$

4.7 Apparent Viscosity versus Shear Rate for NCAW at 25

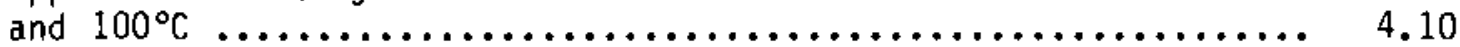

4.8 Apparent Viscosity versus Shear Rate for NCAW5.5 at 25

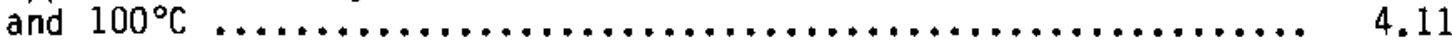

4.9 Apparent Viscosity versus Shear Rate for NCAW1:1 at 25 and $100^{\circ} \mathrm{C}$

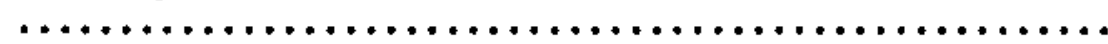

4.10 NCAW Suspended Solids Settling Curve at 25 and $100^{\circ} \mathrm{C} \ldots \ldots \ldots \ldots .4 .15$

4.11 NCAW5.5 Suspended Solids Settling Curve at 25 and $100^{\circ} \mathrm{C} \ldots \ldots .4 .18$

4.12 NCAWl:1 Suspended Solids Settling Curve at 25 and $100^{\circ} \mathrm{C} \ldots \ldots .4 .23$

5.1 Metzner and Reed Friction Factor - Re Relationships ......... 5.4

5.2 Yield-Pseudoplastic Design Curve $-f$ Versus $\operatorname{Re}(n=0.7) \ldots . .65$

5.3 Yield-Pseudoplastic Design Curve - $f$ Versus Re $(n=0.5) \ldots . . .5 .7$ 
5.4 Hanks' Calculation Procedure for the Flow of Yield-Pseudoplastic

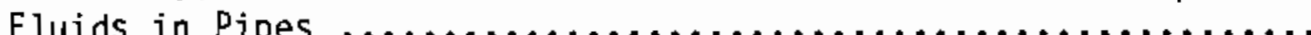

6.1 Effects of Pressure Applied and Fluid Veiocity on the Resuspension of Settled Solids

\section{TABLES}

1 Predictions of Full-Scale Pressure Drop $\ldots \ldots \ldots \ldots \ldots \ldots \ldots \ldots$ iv

2 Comparison of NCAW and NCRW Slurry Properties at $25^{\circ} \mathrm{C} \ldots \ldots \ldots v$

2.1 Equations for Time-Independent Non-Newtonian Fluids ........ 2.4

3.1 Composition of NCAW from Tank 101 AZ $\ldots \ldots \ldots \ldots \ldots \ldots \ldots \ldots \ldots . . \ldots \ldots$

3.2 ICP and IC Analysis of Simulated NCAW Supernatant .......... 3.3

4.1 Physical Properties of Neutralized Current Acid Waste (NCAW)

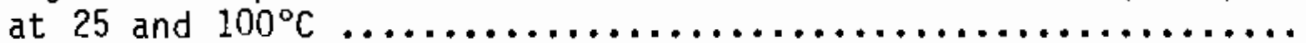

4.2 Settling Rates and Resuspendability Index for NCAW

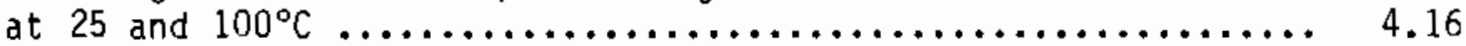

4.3 Physical Properties of NCAw5.5 at 25 and $100^{\circ} \mathrm{C} \ldots \ldots \ldots \ldots . \ldots . \ldots$

4.4 Settling Rates and Resuspendabbility Index for NCAW5.5

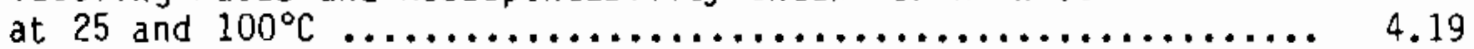

4.5 Physical Properties of NCAWl:1 at 25 and $100^{\circ} \mathrm{C} \ldots \ldots \ldots \ldots \ldots$

4.6 Settling Rates and Resuspendability Index for

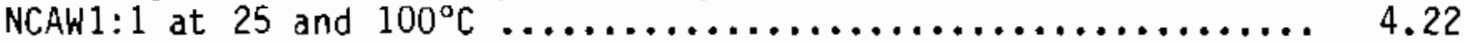

5.1 Hanks' Equations for the Flow of Yield-Pseudoplastic Fluids

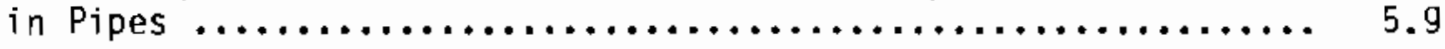

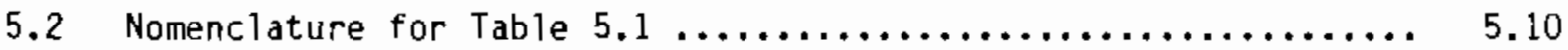

6.1 Predictions of Full-Scale Critical Flow Properties:

Pseudoplastic Model .............................. 6.2

6.2 Predictions of Full-Scale Critical Flow Properties for NCAW1:1 Yield-PseudopTastic Model .................... 6.3

6.3 Assumptions in Full-Scale Pressure Drop Calculations ......... 6.4

6.4 Prediction of Full-Scale Pressure Drop: seudoplastic Mode? 
6.5 Prediction of Full-Scale Pressure Drop:

Yield-Pseudoplastic Model ......................... 6.6

6.6 Comparison of NCAW and NCRW Slurry Properties at $25^{\circ} \mathrm{C} \ldots \ldots \ldots .6$ 
.

-

- 


\subsection{INTRODUCTION AND DBUECTIVES}

The Hanford Plutonium and Uranium Extraction (PUREX) Plant, located in Richland, Washington, was designed to recover plutonium and uranium products from irradiated fuel. After the Zircaloy cladding is dissolved from the fuel elements, the plutonium and uranium are dissolved in nitric acid. The solution is sent to a solvent extraction system to recover, separate and purify the uranium and plutonium.

The first solvent extraction column separates plutonium and uranium from an aqueous feed stream. The aqueous waste stream containing the fission products from this first column, referred to as current acid waste (CAW), is concentrated and treated with sucrose solution to reduce the nitric acid content. The concentrated, partialiy denitrated CAW is then neutralized with 19 molar (M) sodium hydroxide $(\mathrm{NaOH})$ to an excess free-hydroxide $\left(\mathrm{OH}^{-}\right)$concentration of 1M (Kirch 1984).

The neutralized CAW (NCAW) is stored in double-shell tanks (DSTs) at Hanford where the sodium concentration is allowed to reach $5 \mathrm{M}$. Airlift circulators are used in these tanks to keep the aging waste solids from settling to the bottom. However, some thermally and radiologically hot particles have settled in the bottom of the tank.

Neutralized current acid waste will be transported from the DSTs to B-Plant for processing before permanently disposing of the waste.

Rockwell Hanford Operations (Rockwell) has proposed the following method for the first retrieval of NCAW from a DST. NCAW will be pumped from the DST while the airlift circulators are operating until the level of slurry in the tank is below the top of the circulators. At this point, the circulators will be assumed inoperable. The slurry will then be allowed to settle, and the supernatant will be decanted. Because up to $60 \mathrm{in.}$ of solids may have settled in the tank at this point, sluicing may be required to retrieve the solids.

The NCAW in the tank will either be retrieved as is, i.e., no change in the concentration presently in the tank, or will be slightly concentrated before retrieval. For this report, three concentrations of simulated NCAW were 
evaluated that would simulate the different retrieval options: 1) NCAW in the concentration that is currently in the tank, 2) a slightly concentrated NCAW, and 3) equal parts of NCAW settled solids and water.

The slightly concentrated NCAW slurry will be obtained by evaporating some of the water in the supernatant until the sodium concentration in the supernatant reaches $5.5 \mathrm{M}$ (NCAW5.5). The one-to-one volume ratio of NCAW settled solids and flushing water, which simulates the slurry that would result from sluicing, is referred to as NCAwl:l.

Information about the rheological and physical properties must be known to size the transport equipment. This report evaluates the properties of simulated NCAW slurries to determine their flow characteristics. Flow characteristics must be established for the transfer and storage of NCAW to prevent line plugging, particle segregation, cementation and caking. Transfer lines, pumps or jets, and agitation systems must be specifically designed to handle each slurry. The design of this equipment will be guided by the rheological properties of each slurry.

Rheology is the field of study concerned with the deformation and flow of materials. The goal of this NCAW evaluation was to identify the critical fluid flow properties of three concentrations of NCAW at two temperatures, 25 and $100^{\circ} \mathrm{C}$. The specific objectives of the evaluation were to: 1) prepare six samples of each concentration (three per temperature) according to a recipe provided by PNL chemists and approved by Rockwel1; 2) perform lab-scale rheological (type of slurry, yield stress, resuspendability) and physical property evaluations ( $\mathrm{pH}$, density, solids concentration, settling rate) of the three NCAW slurries at two temperatures, 25 and $100^{\circ} \mathrm{C}$; and 3 ) use available rheological models and lab-scale information to predict the fluid flow behavior that the NCAW slurries are likely to exhibit as they are pumped through cylindrical pipe networks.

This report initially sumarizes the theoretical foundation of slurry flow systems. Section 2 of this report describes the classical rheological models that are used to describe homogeneous and heterogeneous flow systems. Because the results obtained here are only valid for the slurries utilized, Section 3 , Preparation of Simulated Current Acid Waste, describes how the slurries were 
prepared. The laboratory-scale viscometric and physical property information obtained is summarized in Section 4, Laboratory Rheological Evaluations. Section 5, Rheological Models for Flow in Pipes, discusses the analytical models used to determine critical Reynolds numbers and associated pipe flow parameters. Laboratory results are scaled up using the models in Section 5 to establish engineering design requirements for a full-scale transfer system in Section 6. 


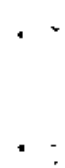

'

•

.

. 


\subsection{SLURRY FLOW SYSTEMS}

Rheology is the field of study concerned with the deformation and flow of materials. The procedures used to design slurry transport processes are based on classical rheological models for homogeneous and heterogeneous flow systems. These models were used to classify NCAW slurries, and to scale up the laboratory data collected to predict the behavior of the slurries in a fullscale transport system. The theoretical models used to define the fluid flow behavior of slurries are described in this section.

\subsection{CLASSIFICATION OF SLURRIES}

A complex mixture can be defined as a single-phase, non-Newtonian fluid, a multiphase mixture of a fluid and a solid, or a mixture of two or more fluids. A classification of complex mixtures based on the effect of phase condition or flow behavior is depicted on Figure 2.1. A multiphase mixture can be classified as a fine dispersion, a coarse dispersion, a macro-mixed flow pattern, or as a stratified flow pattern.

Macro-mixed and stratified heterogeneous flow behavior applies to gasliquid and liquid-liquid mixtures. Examples of a macro-mixed flow are frothy and highly turbulent mixtures of gas and liquid or of immiscible liquids under

\begin{tabular}{|c|c|c|c|c|c|}
\hline \multirow{2}{*}{ Single Phase } & \multicolumn{5}{|c|}{ Multi-Phase (Gas-Liquid, Liquid-Liquid, Gas-Solid, Liquid-Solid) } \\
\hline & \multicolumn{2}{|c|}{ Fine Dispersion } & $\begin{array}{c}\text { Coarse } \\
\text { Dispersion }\end{array}$ & Macro-Mixed & Stratified \\
\hline \multirow{2}{*}{$\begin{array}{c}\text { True } \\
\text { Homogeneous }\end{array}$} & \multicolumn{2}{|c|}{ Pseudo- Homogeneous } & \multirow{2}{*}{\multicolumn{3}{|c|}{ Heterogeneous }} \\
\hline & $\begin{array}{l}\text { Laminar } \\
\text { Turbulent }\end{array}$ & $\begin{array}{c}\text { Turbulent } \\
\text { Only }\end{array}$ & & & \\
\hline \multirow{2}{*}{\multicolumn{2}{|c|}{$\begin{array}{l}\text { Flow Behavior } \\
\text { as Single Phase }\end{array}$}} & & \multirow{2}{*}{\multicolumn{2}{|c|}{$\begin{array}{l}\text { Flow Behavior } \\
\text { as Multi-Phase }\end{array}$}} & \\
\hline & & & & & \\
\hline
\end{tabular}

FIGURE 2.1. Classification of Complex Mixtures 
conditions where neither phase is continuous. Stratified flow exists when each phase of a gas-liquid mixture or a mixture of two immiscible liquids is continuous.

For Tiquid-solid slurries, a fine dispersion is a mixture of fine particles of solids that are uniformly dispersed in a continuous liquid phase. Solids with a diameter less than about 40 um usually form fine dispersions and can be considered to be pseudohomogeneous mixtures (Bain and Bonnington 1970). Solid particles with a diameter greater than about 40 um usually form coarse dispersions, have a tendency to settle, and can be considered to be heterogeneous mixtures. The techniques used to design transport and treatment systems to achieve pseudohomogeneous and heterogeneous mixtures differ markedly. These procedures are described in Section 2.3.

\subsection{PSEUDOHOMOGENEOUS MIXTURES}

Viscous, single-phase fluids and pseudohomogeneous multiphase fluid mixtures are classified according to their response to shearing stresses. A shear stress is defined as:

$$
\tau=\frac{F}{A}
$$

where $\tau=$ shear stress, dynes $/ \mathrm{cm}^{2}$

$F=$ force, dynes

$A=$ area, $\mathrm{cm}^{2}$

For Newtonian fluids in laminar flow:

$$
\tau=\frac{d v}{d y}
$$

$$
\text { where } \begin{aligned}
\tau & =\text { shear stress, dynes } / \mathrm{cm}^{2} \\
\mu & =\text { viscosity, dynes } / \mathrm{cm}^{2} \cdot \sec \\
\frac{d v}{d y} & =\text { shear rate in y direction, } \mathrm{sec}^{-1}
\end{aligned}
$$


The viscosity $\mu$, is a proportionality constant that is independent of shear rate and affected only by pressure and temperature for a fluid system. A plot of shear stress versus rate of shear in the laminar flow region is known as a rheogram (see Figure 2.2a). The slope of the curve is constant for a Newtonian fluid. Non-Newtonian fluids are those that display rheograms that are not linear through the origin at a given temperature and pressure. Non-Newtonian fluids are usually classified as time-independent, time-dependent or viscoelastic fluids.

\subsubsection{Time-Independent Non-Newtonian Fluids}

Time-independent non-Newtonian fluids are fluids for which rate of shear at a given point is solely dependent upon instantaneous shear stress at the point. Rheograms for classical time-independent non-Newtonian fluids are depicted on Figure 2.2a. The relationship between apparent viscosity and shear rate for these fluids is described on Figure $2.2 b$.

\subsubsection{Fluids Without a Yield Stress}

Dilatant and pseudoplastic non-Newtonian slurries do not exhibit a shear stress at a shear rate of zero. Pseudoplastic and dilatant materials exhibit a continuous variation of shear stress with shear rate, the slope of the curve decreasing (pseudoplastic) or increasing (dilatant) as shear rate increases (see Figure 2.2a). Equations that relate shear stress and shear rate for these fluids are included in Table 2.1.

(a)

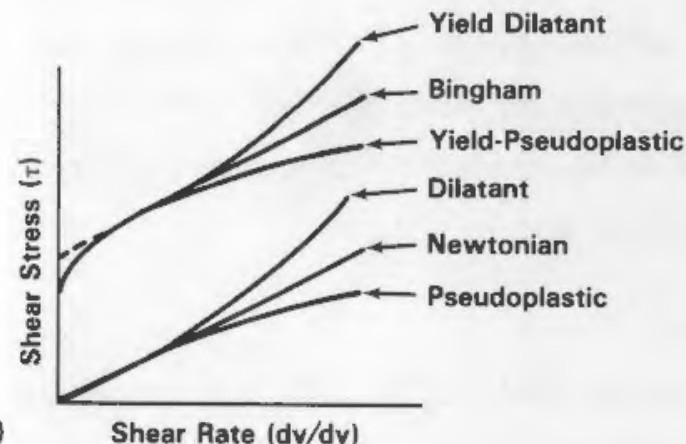

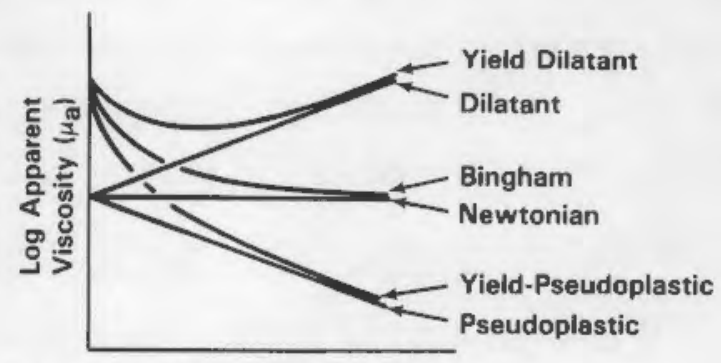

(b)

FIGURE 2.2. Rheograms for Time-Independent Non-Newtonian Fluids 
TABLE 2.1. Equations for Time-Independent Non-Newtonian Fluids

\begin{tabular}{|c|c|c|c|c|}
\hline Type of Fluid & General Equation & -7 & $n$ & $\mathrm{~K}$ \\
\hline Yield-Dilatant & $\tau-\tau_{y}=K\left(\frac{d v}{d y}\right)^{n}$ & $>0$ & $>1$ & -- \\
\hline Dilatant & $\tau=k\left(\frac{d y}{d y}\right)^{n}$ & $=0$ & $>1$ & -- \\
\hline Yield-Pseudoplastic & $\tau-\tau_{y}=K\left(\frac{d v}{d y}\right)^{n}$ & $>0$ & $<1$ & -- \\
\hline Pseudoplastic & $\tau=K\left(\frac{d v}{d y}\right)^{n}$ & $=0$ & $<1$ & --- \\
\hline Bingham Plastic & $\tau-\tau_{y}=k\left(\frac{d v}{d y}\right)^{n}$ & $>0$ & $=1$ & $\Perp_{p}$ \\
\hline Newtonian & $\tau=k\left(\frac{d v}{d y}\right)^{n}$ & $=0$ & $=1$ & $\mu$ \\
\hline
\end{tabular}

Most non-Newtonian slurries exhibit pseudoplastic behavior. Because the exponent $n$, is less than unity for pseudoplastic fluids (see Table 2.1), the apparent viscosity $K$, decreases with increasing shear rate. Pseudoplastic fluids include rubber solutions, adhesives, polymer solutions, starch suspensions, mayonnaise, soap, detergent slurries, paints, biological sludges, and many other solid-liquid suspensions.

Dilatant fluids are much less common than pseudoplastic fluids. Dilatancy is usually observed only at select solids concentrations in suspensions of irregularly shaped solids. The apparent viscosity of dilatant fluids increases with increasing shear rate because the exponent $n$, (see Table 2.1) is greater than one. Quicksand, wet beach sand, and some aqueous suspensions of titanium dioxide are examples of dilatant fluids (Skelland 1967).

\subsubsection{Fluids With a Yield Stress}

Bingham plastic, yield pseudoplastic and yield-dilatant pseudohomogeneous slurries exhibit a yield stress at a zero shear rate. This yield stress is caused by the internal structure created by the small particles in the fluid. The structure of particles prevents movement of the fluid for values of the 
shear stress $\tau$, less than the yield value, $\tau_{y}$. When $\tau$ exceeds $\tau$, the internal particle structure changes, and fluid movement begins. Empirical equations that describe these fluids are included in Table 2.1.

Bingham plastic fluids include thickened hydrocarbon greases, some asphalts and bitumens, and a variety of emulsions. The most common Bingham fluids include water suspensions of clays, fly ash, quartz, metallic oxides, sewage sludge and paint systems. Yield-pseudoplastic materials include claywater suspensions, solutions of carbonpolymethylene (carbopol), some grout formulations, rubber-benzene solutions, phosphate ore and many coal-water slurries.

Yield-dilatant fluids are much less common than Bingham plastic or yieldpseudoplastic fluids. Yield-dilatant fluids will begin to flow when their yield stress is exceeded. Once motion begins, the rate of increase in shear stress with velocity gradient increases as the velocity gradient increases. Some solutions of titania (Metzner and Whitlock 1958), magnetite, and galena (Govier, Shook and Lilge 1957) can exhibit this behavior.

\subsubsection{Time-Dependent Non-Newtonian Fluids}

The behavior of time-independent non-Newtonian fluids adjusts instantaneously as shear stresses are applied. The structural configuration and particle orientation of some slurries cannot adjust instantaneously to changes in shear stresses. These time-dependent non-Newtonian fluids are usually classified as thixotropic or rheopectic slurries. Rheograms for these slurries are depicted on Figure 2.3.

Thixotropic slurries exhibit a decrease in shear stress with time at a constant shear rate and temperature. A hysteresis loop (Figure 2.3) will result as the shear rate is steadily increased from zero to a maximum value and then decreased steadily back to zero. The internal particle alignment mechanisms responsible for thixotropic behavior are similar to, but occur at a slower rate than those causing pseudoplastic behavior. Some oil-well drilling muds, greases, margarines, shortenings, printing inks, and high molecular 


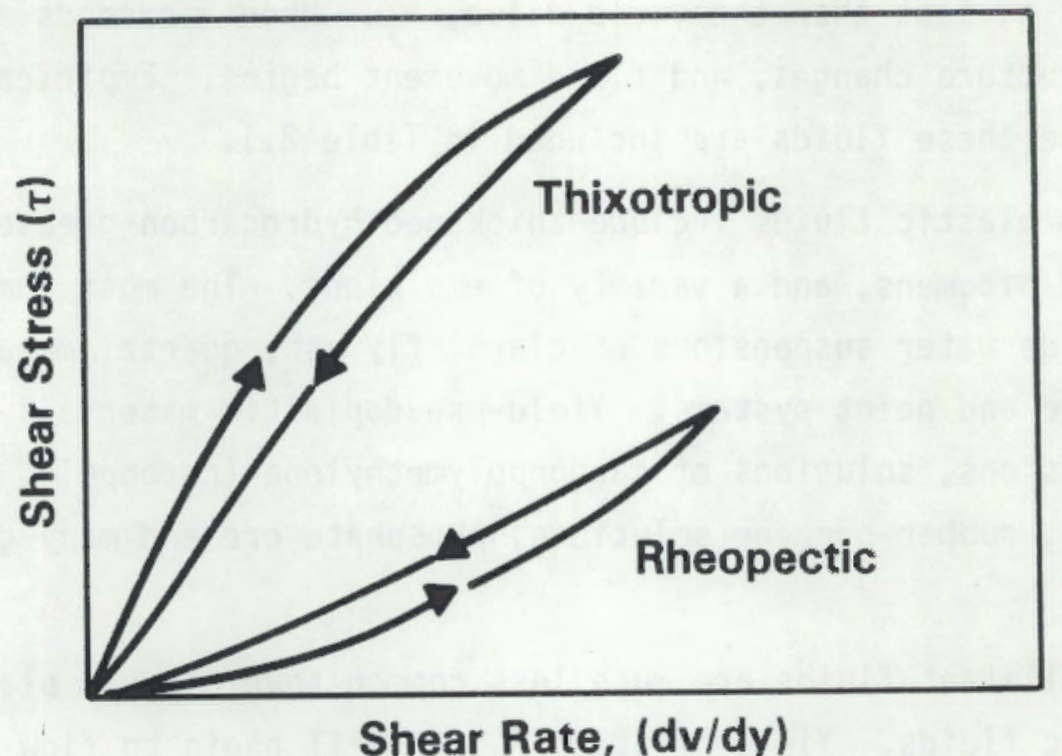

FIGURE 2.3. Rheograms for Thixotropic and Rheopectic Non-Newtonian Fluids

weight polymers exhibit thixotropic behavior (Jobling and Roberts 1959). Extensive surveys of thixotropic behavior have been prepared (Govier and Aziz 1982).

Rheopectic slurries exhibit an increase in shear stress with time at a constant shear rate and temperature. A hysteresis loop (Figure 2.3) will result as the shear rate is steadily increased from zero to a maximum value and then decreased steadily back to zero. The hysteresis loop produced is a reverse image of the loop created by thixotropic materials. The internal particle alignment mechanisms responsible for rheopectic behavior are similar too, but occur at a slower rate than those causing dilatant behavior. Some bentonite clays, vanadiam pentoxide, gypsum and ammonium oleate suspensions exhibit rheopectic behavior (Skelland 1967). Extensive surveys of rheopectic behavior have been prepared (Bauer and Collins 1967).

\subsubsection{Viscoelastic Fluids}

Viscoelastic fluids exhibit time-dependent non-Newtonian viscous behavior and elastic recovery properties. They flow when subjected to stress but part of their deformation is gradually recovered when the stress is removed. Viscoelastic fluids include bitumens, flour dough, nylon, and nearly all molten 
polymers. Solid-liquid slurries rarely display significant degrees of viscoelastic behavior. Constitutive equations that describe viscoelastic behavior have been developed (Skelland 1967; Govier and Aziz 1982).

\subsection{HETEROGENEOUS FLOW SYSTEMS}

A heterogeneous slurry is a complex mixture of coarse particles in a liquid stream. The solids may not be homogeneously dispersed in the liquid stream. The pseudohomogeneous, non-Newtonian behavior described in Section 2.2 cannot be applied to heterogeneous slurries. These slurries act as two-phase systems. The degree of phase separation is a function of particle size, shape, density, and concentration; and the fluid density and viscosity.

\subsubsection{Heterogeneous Slurry-Flow Patterns}

A qualitative flow curve (Figure 2.4) is often used to differentiate heterogeneous slurry flow patterns (Govier and Aziz 1982) in pipes. The flow curve is a plot on a logarithmic scale of the pressure drop developed by the slurry as a function of the slurry transport velocity. At sufficiently high velocities, the slurry flows as a pseudohomogeneous suspension. As the velocity decreases, a heterogeneous concentration profile (Figure 2.5) develops. At still lower velocities, a sliding bed forms at the bottom of the pipe (Figure 2.5). The velocity at which the flow pattern changes from a heterogeneous to a sliding regime is known as the "sliding bed velocity" or the "critical deposition velocity" (Hanks and Sloan 1981). The sliding bed velocity $V_{c d}$, usually corresponds with the minimum of the pressure gradientvelocity curve. As the mixture velocity is decreased still further, the lower portion of the sliding bed becomes stationary, although particles at the top of the bed may continue to move by saltation. The transition from the sliding bed regime to the stationary bed-saltation flow regime is known as the "stationary bed velocity." Slurry transport systems are usually designed to provide line velocities that exceed the critical deposition velocity, $V_{c d}$.

Particle size distribution, density and shape, fluid density and viscosity, the diameter of the transfer pipe, and many other factors will impact the value of the critical deposition velocity. For rigid, spherical particles with a specific gravity of 2.65 , it has been suggested (Govier and Aziz 1982) that: 


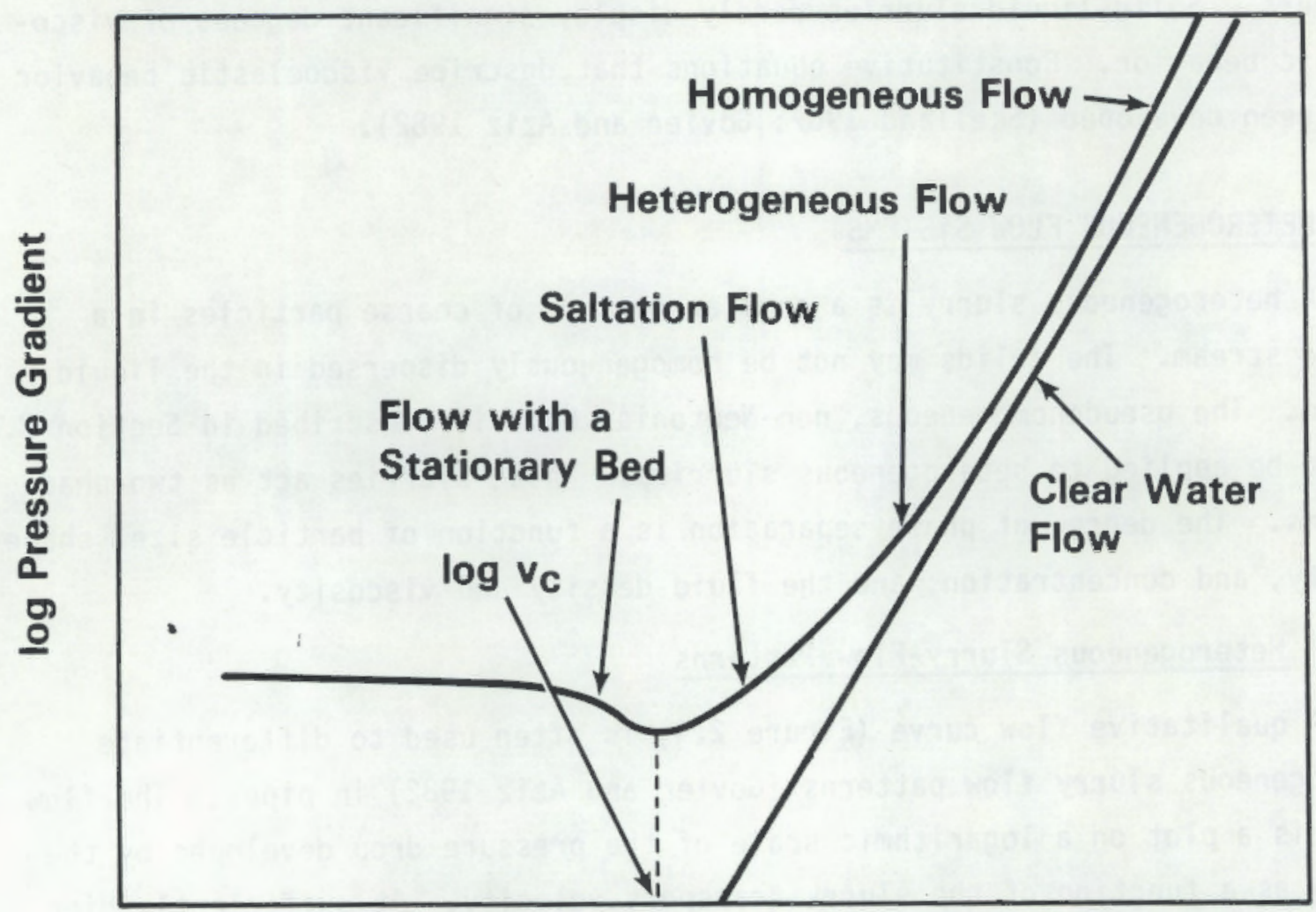

log Transport Velocity

FIGURE 2.4. Flow Curve for Heterogeneous Slurries

- ultrafine particles, ten microns or smaller, are almost always carried in a fully suspended state

- fine particles, 10 to 100 microns, are usually carried in a fully suspended state, but concentration gradients due to gravitational effects may be encountered

- medium-sized particles, 100 to 1000 microns, may be fully suspended at sufficiently high velocities but often will form a moving bed at the bottom of the pipe; in all cases a concentration gradient will exist

- coarse particles, 1000 to 10,000 microns, are seldom fully suspended, and usually form a moving deposit on the bottom of a pipe 

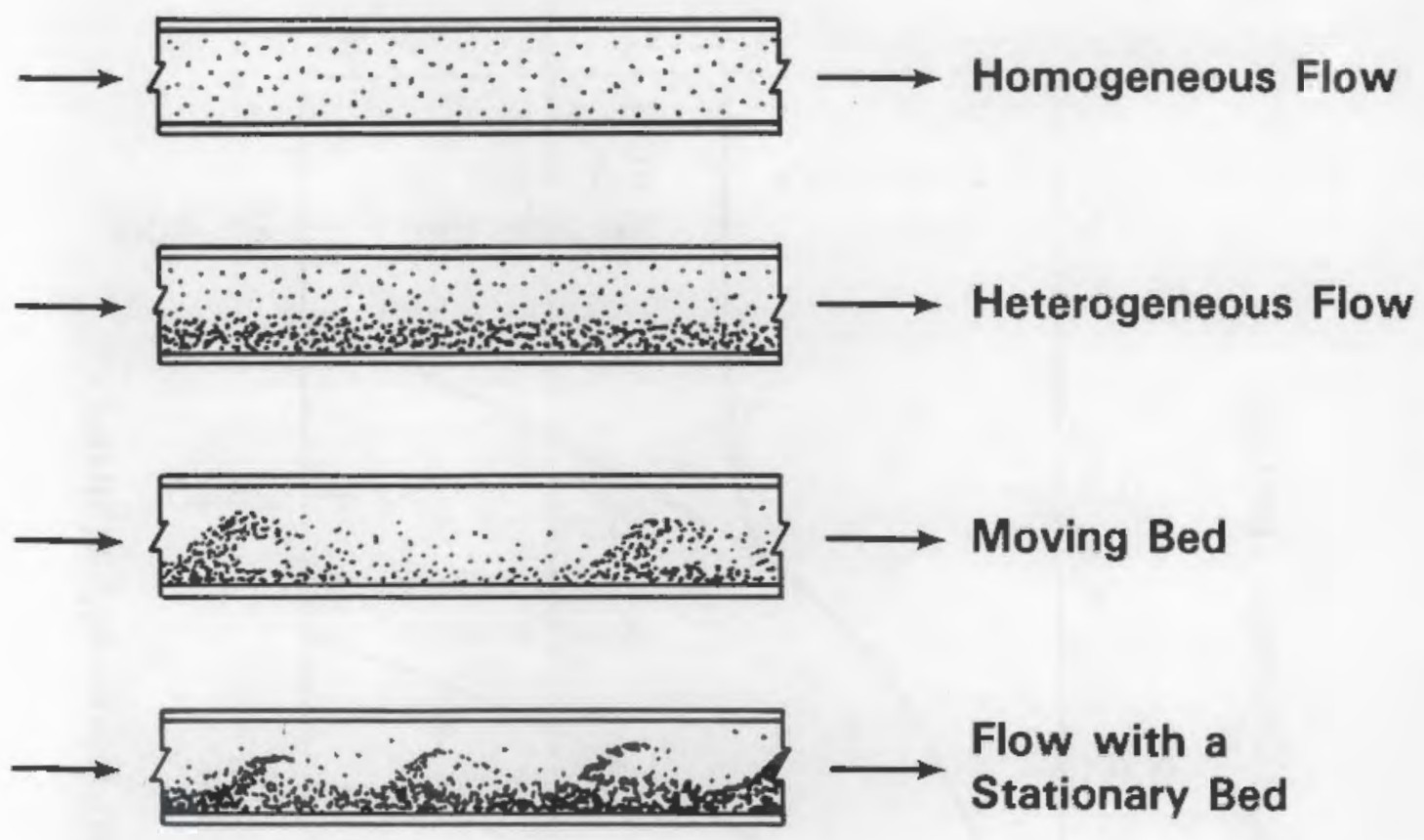

\section{Flow with a} Stationary Bed

\section{FIGURE 2.5. Heterogeneous Slurry Flow Patterns}

- very large particles, larger than 10,000 microns, are not suspended at normal velocities unless they are unusually light and may be transported in a fluid only as a moving bed on the bottom of a pipe.

These guidelines are useful for estimating the type of heterogeneous flow pattern that may exist for differing particle sizes.

Similar guidelines that relate heterogeneous flow patterns to particle size and line velocity have been reported (Newitt et al. 1955). They relate specifically to the transport of graded sand in a 6-in. diameter pipe. These guidelines are shown on Figure 2.6. They are useful for estimating the type of heterogeneous flow pattern that may exist for differing particle diameters and velocities. 


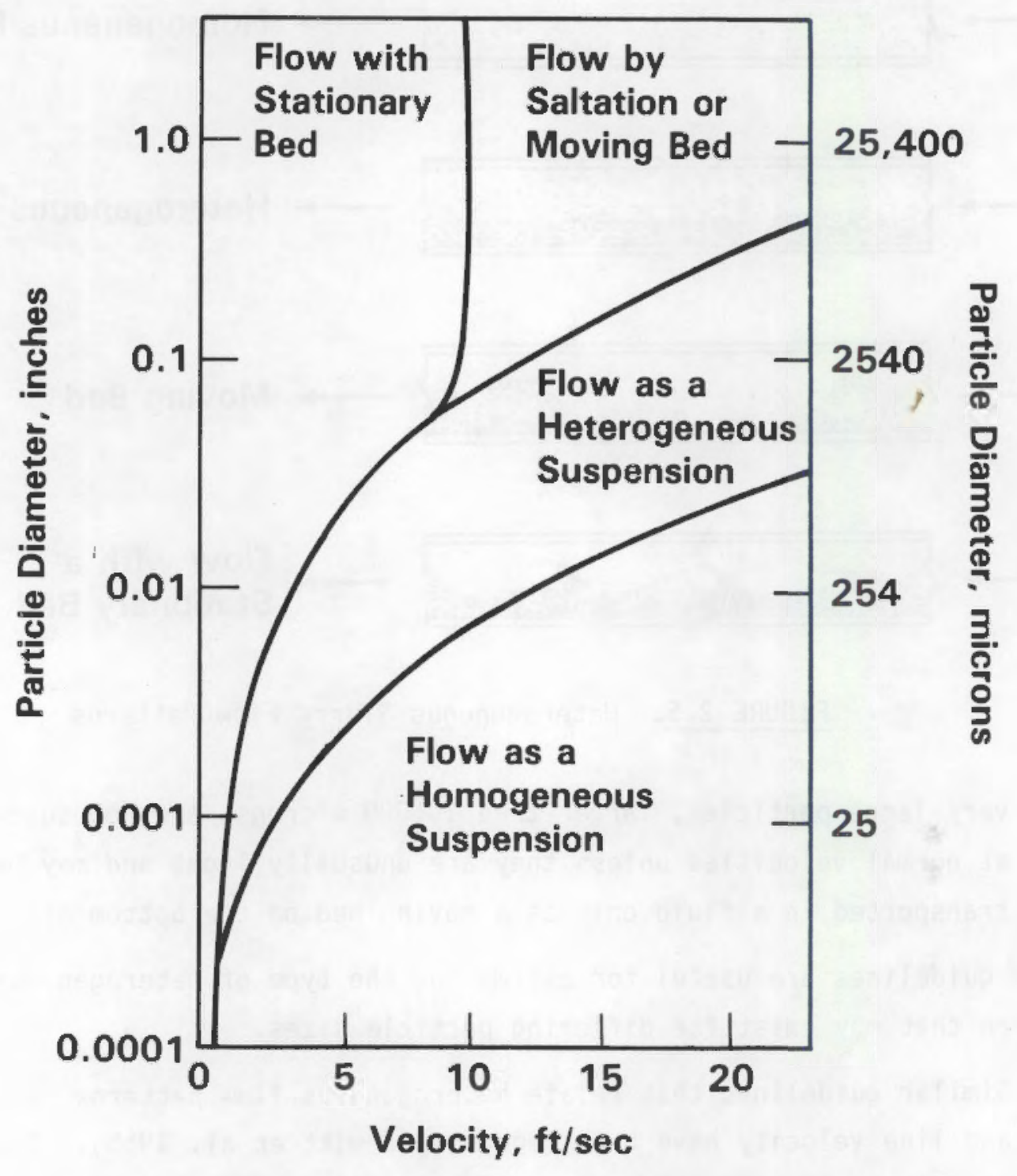

Reference: (Newitt et al. 1955)

FIGURE 2.6. Heterogeneous Slurry Flow Patterns; Particle Diameter and Velocity Effects 


\subsection{PREPARATION OF SIMULATED CURRENT ACID WASTE}

At PUREX, CAW is neutralized with $19 \mathrm{M}$ sodium hydroxide to a minimum of $1 M$ excess hydroxide ions using a direct-strike method. The NCAW is stored in DSTs on the Hanford Site. NCAW will be transported from the DSTs to B-Plant for processing before permanently disposing of the waste.

The NCAW in the first tank will either be retrieved as is, i.e., no change in the concentration presently in the tank, or will be slightly concentrated before retrieval. For this report, three concentrations of simulated NCAW were evaluated that would simulate the different retrieval options: 1) NCAW in the concentration that is currently in the tank, 2) a slightly concentrated NCAW (NCAW5.5), and 3 ) equal parts of NCAW settled solids and water (NCAW1:1), simulating a possible sluicing stage.

In November 1985, Rockwell retrieved a sample of NCAW from tank $101 \mathrm{AZ}$. The composition of this sample is presented in Table 3.1. The simulated NCAW composition prepared in the laboratory parallels this composition. The preparation of simulated NCAW and the two other concentrations used during this laboratory-scale evaluation will be described here.

\subsection{LABORATORY PREPARATION PROCEDURES}

To best simulate NCAW, it was decided to "back out" the composition of simulated CAW from an analysis of the composition of NCAW in Tank 101AZ and neutralize it. The simulated neutralized CAW would be digested for 100 hours at $100^{\circ} \mathrm{C}$ to simulate the aged waste. The detailed procedures used by PNL and approved by Rockwell to prepared NCAW are described in the following paragraph.

To prepare simulated NCAW, a neutral nitrate salt stock solution was made. It contained all the metal ions that would readily go into solution. Hydrofluoric, nitric, sulfuric and phosphoric acid and sodium molibdate were added to the stock solution, and it was heated to $70^{\circ} \mathrm{C}$ before being neutralized. This acid solution was neutralized with 19M sodium hydroxide using the direct-strike method. Once neutralized, sodium nitrite and sodium carbonate were added to the solution. These constituents were added after neutralization 
TABLE 3.1. Composition of NCAW from Tank $101 \mathrm{AZ}$

\begin{tabular}{|c|c|c|c|}
\hline Component & $\begin{array}{c}\text { Overall } \\
\text { Composition (a) } \\
\text { (moles/liter NCAW) } \\
\end{array}$ & $\begin{array}{c}\text { Supernate } \\
\text { (moles/liter } \\
\text { supernate) } \\
\end{array}$ & $\begin{array}{l}\text { Centrifuged Solids } \\
\text { (moles/liter } \\
\text { centrifuged solids) }\end{array}$ \\
\hline $\operatorname{SpG}(\mathrm{gr} / \mathrm{mL})$ & 1.20 & 1.17 & 1.4 \\
\hline & 0.97 & 1.09 & \\
\hline $\mathrm{SO}_{4}$ & 0.15 & 0.151 & $0.1224(b)$ \\
\hline $\mathrm{NO}_{3}^{4}$ & 1.17 & 1.75 & $1.404(\mathrm{~b})$ \\
\hline $\mathrm{NO}_{2}^{3}$ & 0.43 & 0.44 & $0.348^{(b)}$ \\
\hline $\mathrm{CO}_{3}^{2}$ & 0.22 & 0.20 & 0.40 \\
\hline $\mathrm{Na}$ & 5.02 & 4.89 & $6.1\left(65 \% \mathrm{H}_{2} \mathrm{O}\right.$ soluble $)$ \\
\hline $\mathrm{Al}$ & 0.50 & 0.48 & 0.652 ( $55 \%^{2} \mathrm{H}_{2} \mathrm{O}$ soluble) \\
\hline $\mathrm{k}$ & 0.12 & 0.116 & 0.13 ( $71 \% \mathrm{H}_{2} \mathrm{O}$ soluble) \\
\hline $\mathrm{Ca}$ & $1.93 \times 10^{-02}$ & 0.0026 & $0.154\left(0.84 \% \mathrm{H}_{2} \mathrm{O}\right.$ soluble \\
\hline $\mathrm{Cr}$ & $1.18 \times 10^{-02}$ & 0.0112 & $0.017\left(55 \% \mathrm{H}_{2} \mathrm{O}\right.$ soluble $)$ \\
\hline Ps & $6.53 \times 10^{-04}$ & 0.0004 & $0.0027(c)$ \\
\hline Ms & $7.52 \times 10^{-03}$ & 0.00005 & $0.068(c)$ \\
\hline Mo & $1.16 \times 10^{-03}$ & 0.0009 & $0.0033(c)$ \\
\hline$P$ & $2.30 \times 10^{-02}$ & 0.0173 & 0.069 (c) \\
\hline $\mathrm{F}$ & $8.63 \times 10^{-02}$ & 0.089 & 0.064 (b) \\
\hline C1 & & $<9.07 \times 10^{-3}$ & $<0.017$ (b) \\
\hline S1 & $6.64 \times 10^{-02}$ & & 0.604 (c) \\
\hline $\mathrm{Zr}$ & $4.88 \times 10^{-02}$ & & $0.444(c)$ \\
\hline $\mathrm{Ba}$ & $9.24 \times 10^{-04}$ & & 0.0084 (c) \\
\hline B & $7.44 \times 10^{-03}$ & & 0.0676 (c) \\
\hline$C d$ & $6.64 \times 10^{-03}$ & & 0.0604 (c) \\
\hline $\mathrm{Ce}$ & $1.55 \times 10^{-03}$ & & $0.0141(c)$ \\
\hline Co & $7.70 \times 10^{-05}$ & & $0.0007(c)$ \\
\hline $\mathrm{Cu}$ & $4.07 \times 10^{-04}$ & & 0.0037 (c) \\
\hline La & $9.24 \times 10^{-04}$ & & 0.0084 (c) \\
\hline Nd & $1.43 \times 10^{-03}$ & & $0.013(c)$ \\
\hline $\mathrm{Ni}$ & $9.02 \times 10^{-03}$ & & $0.082^{(c)}$ \\
\hline $\mathrm{Pd}$ & $1.21 \times 10^{-02}$ & & 0.11 (c) \\
\hline $\mathrm{Aa}$ & $1.43 \times 10^{-04}$ & & $0.0013(c)$ \\
\hline Sr & $4.62 \times 10^{-04}$ & & 0.0042 (c) \\
\hline $\mathrm{Ti}$ & $1.32 \times 10^{-04}$ & & 0.0012 (c) \\
\hline $\mathrm{Zn}$ & $5.28 \times 10^{-04}$ & & $0.0048(c)$ \\
\hline $\mathrm{Fe}$ & $7.35 \times 10^{-02}$ & & 0.668 (c) \\
\hline & $2.09 \times 10^{-03}$ & & $0.019^{(c)}$ \\
\hline
\end{tabular}

(a) Overall composition is based on 89 vol\% supernate and 11 vol\% centrifuged solids.

(b) Present in water soluble solids/interstitial liquid.

(c) Present in acid $\left(\mathrm{HNO}_{3} / \mathrm{HF}\right)$ soluble solids. 
because they would not go into solution in an acidic environment. Finally, the sludge-supernatant was heated with refluxing for 100 hours.

A 1-liter batch of simulated NCAW was prepared and digested with refluxing for 100 hours. The supernatant was analyzed using an inductively coupled argon plasma atomic emission spectroscopy (ICP) analysis and an ion chromatograph (IC) analysis. A summary of the results are presented in Table 3.2.

The composition listed in Table 3.2 agrees closely with the target compositions listed in Table 3.1. This agreement was considered adequate to proceed with the evaluation. The 1-liter batch was separated into 6 samples; 3 for the rheological and physical properties evaluations of NCAW at $25^{\circ} \mathrm{C}$, and 3 for the same evaluations of NCAW at $100^{\circ} \mathrm{C}$.

One other analysis was performed on the NCAW supernatant. Chemists from Pacific Northwest Laboratory and Rockwell performed separate titration analyses to determine the amount of excess hydroxide present in supernatant. The PNL analysis resulted in a reported value of $1.4 M$ excess hydroxide ion in NCAW while the Rockwell analysis reported a value of $1.24 \mathrm{M}$ excess hydroxide ion. The target value was $1 M$ excess hydroxide ion.

An important factor in rheological evaluations of slurries is the vol\% settled solids. The vol\% settled solids of $6 \%$ NCAW is nearly constant at free hydroxide ion concentrations greater than IM (Jansky and Kronvall 1982).

TABLE 3.2. ICP and IC Analysis of Simulated NCAW Supernatant

\begin{tabular}{|c|c|}
\hline Constituent & Concentration \\
\hline $\mathrm{Al}$ & 0.48 \\
\hline $\mathrm{Ca}$ & $3.5 \times 10^{-5}$ \\
\hline $\mathrm{Cr}$ & 0.006 \\
\hline K & 0.107 \\
\hline Mo & $9 \times 10^{-4}$ \\
\hline $\mathrm{Na}$ & 4.78 \\
\hline $\mathrm{P}$ & 0.0152 \\
\hline Cs & $1.35 \times 10^{-3}$ \\
\hline $\mathrm{SO}_{4}$ & 0.125 \\
\hline $\mathrm{NO}_{3}^{4}$ & 1.935 \\
\hline $\mathrm{NO}_{2}$ & 0.565 \\
\hline $\mathrm{Cl}^{2}$ & 0.014 \\
\hline $\mathrm{OH}$ & 1.4 \\
\hline
\end{tabular}


Therefore, although the excess hydroxide ion is greater than the target value, the vol\% of settled solids is the same. The rheology of NCAW with slightly greater than $1 M$ excess hydroxide ion should not be significantly different from the rheology of NCAW with IM excess hydroxide ion.

Simulated NCAW5.5 was prepared by concentrating a second 1-1iter batch of NCAW. The NCAW was concentrated to a 5.5-M sodium concentration in the supernatant by evaporating some of the supernatant. The volume reduction required to increase the sodium concentration in the supernatant was calculated using the following equation:

$\left(\begin{array}{l}\text { Sodium concentra- } \\ \text { tion in NCAW } \\ \text { supernatant }\end{array}\right)\left(\begin{array}{c}\text { Volume of NCAW super- } \\ \text { natant in slurry }\end{array}\right)=(5.5-M)\left(\begin{array}{l}\text { Volume of NCAW5.5 } \\ \text { supernatant in } \\ \text { slurry }\end{array}\right)$

$$
(4.78 \mathrm{M})(850 \mathrm{~mL})=(5.5 \mathrm{M})(\mathrm{X} \mathrm{mL})
$$

The concentrated NCAW (NCAW5.5) was separated into six aliquots; three samples for the rheological and physical properties evaluations of NCAW5.5 at $25^{\circ} \mathrm{C}$, and three for the same evaluations of NCAW5.5 at $100^{\circ} \mathrm{C}$.

Simulated NCAW1:1 was prepared by centrifuging a third batch of NCAW. The centrifuged solids of the simulated NCAW were approximately 15 vol\% compared to approximately 11 vol\% expected for the actual NCAW. The centrifuged NCAW solids were mixed with one volume of NCAW supernatant to simulate NCAW settled solids. This mixture of settled solids was mixed with one volume of tap water. In summary, NCAW1:1 is 25 vol\% centrifuged solids, 25 vol\% supernatant, and 50 vol\% tap water. As with NCAW and NCAW5.5, the batch of NCAW1:1 was separated into six samples.

The supernatants of all three slurries were clear (rather than cloudy) and yellow. The NCAWl:1 supernatant was slightly less yellow than the other two supernatants because of the dilution of the slurry with water. When shaken, the NCAW slurries are chocolate brown and have a consistency that is a little thicker than that of water. 


\subsection{LABORATORY RHEOLOGICAL EVALUATIONS}

Laboratory evaluations were performed with NCAW samples prepared at three concentrations and at temperatures of 25 and $100^{\circ} \mathrm{C}$. The concentrations evaluated were: 1 ) as is (NCAW); 2) concentrated NCAW (5.5M Na, NCAW5.5); and 3) a one-to-one volume ratio of settled NCAW solids and water (NCAW1:1). The samples were prepared according to the recipe and procedures in Section 3 . Three samples of each concentration at each temperature were evaluated.

Laboratory evaluations were conducted to: 1) measure the physical properties of the slurries, 2) classify the rheological behavior of each slurry, and 3) provide background information needed to predict full-scale flow characteristics expected for the NCAW slurries in a pump-pipe system.

\subsection{EXPERIMENTAL EQUIPMENT AND PROCEDURES}

Laboratory rheological data were obtained with a Haake Rotovisco viscometer equipped with an M150 measuring/drive head and the NV sensor system. The measurement of viscosity with this instrument (see Figure 4.1 ) requires that the sample be placed into the gap between two coaxial cylinders. A motor drives the inner cylinder. A viscosity-related torque, caused by the resistance of the sample to shearing, acts on the inner cylinder. This torque deflects a measuring spring placed between the motor and the inner cylinder. The magnitude of the spring deflection correlates linearly with the torque, and the spring deflection is transformed into an electrical signal. The torque and tachometer signals are recorded.

The speed signal required for the determination of the shear rate does in fact not come from the rotor directly but from the tacho-generator (TG) which sits above the motor and is mechanically linked to it. For slurries that do not exhibit yield stresses, the speeds of the tacho-generator, motor, and the rotor are identical so that the speed signal $n_{t g}$, also defines the rotor speed $n_{r}$. A slurry with a yield stress will "clamp" the rotor to the cup, until the torque $\tau$, applied is greater than the yield stress $\tau_{y}$.

- Trademark of Haake Buchler Instruments Inc. 

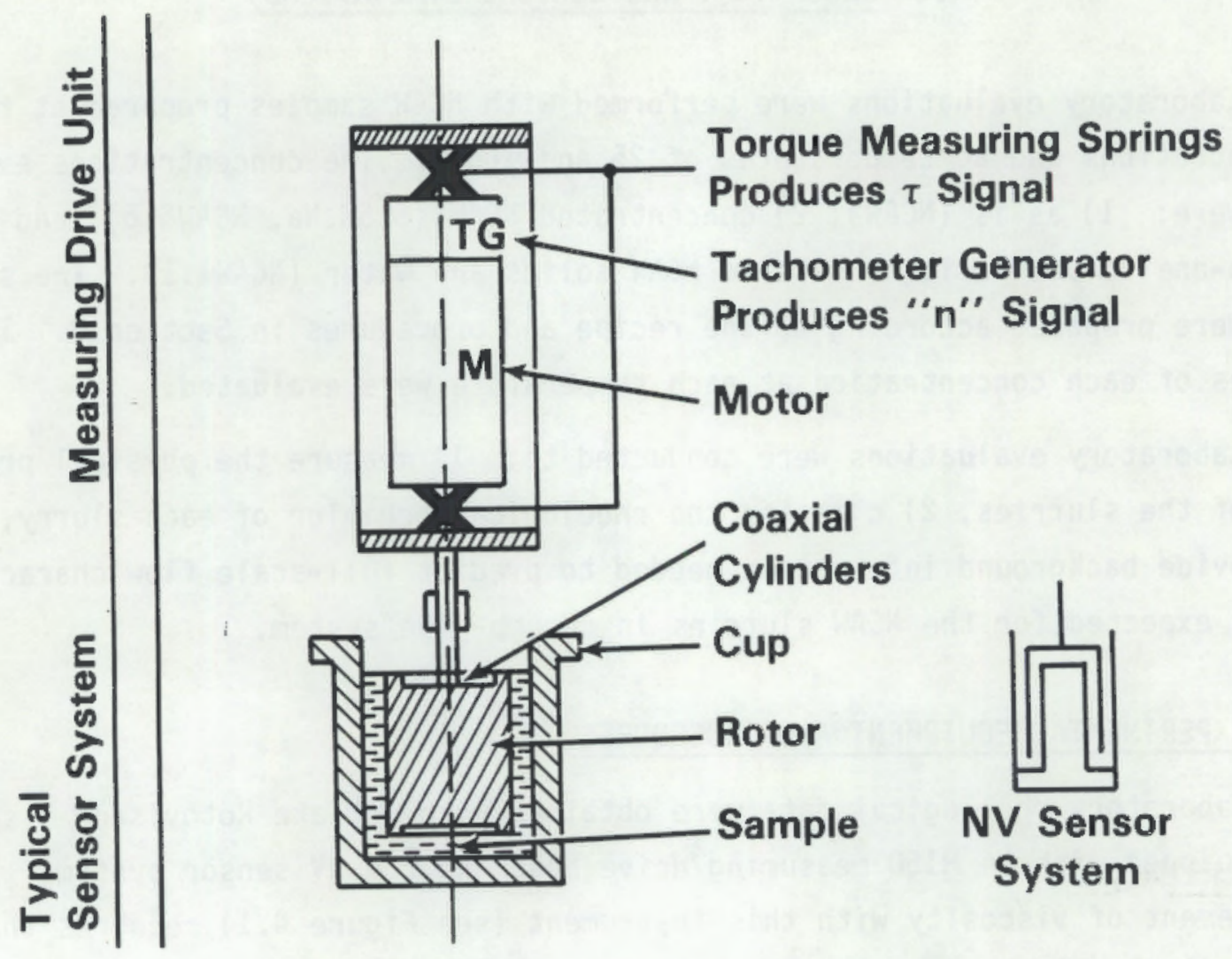

FIGURE 4.1. Schematic of a Haake Rotovisco Viscometer

While the rotor is still clamped and remains at standstill, the motor rotation will cause some spring deflection and consequently a torque signal $\tau$, on the ordinate. For a slurry with a yield stress a straight line, leaning off the vertical with an angle $\beta$ is recorded initially (see figure 4.2 ). When the shear stress surpasses the yield value $\tau_{y}$, the rotor breaks loose from its "clamp," and picks up speed, accelerating almost instantaneously to the value $n_{\mathrm{tg}}$. The change in the behavior of the sample becomes apparent in the rapid turn of the flow curve. The ordinate value of this turning point defines the yield value $\tau_{y}$. On the flow curve two regions can be distinguished: the first region is a segment of the "flow curve of a solid," while the second region describes the flow of the material after it has been transformed into a liquid.

Depending on the test conditions selected, one may also get a more or less gradual change of the flow curve from one region to the other. The transition 


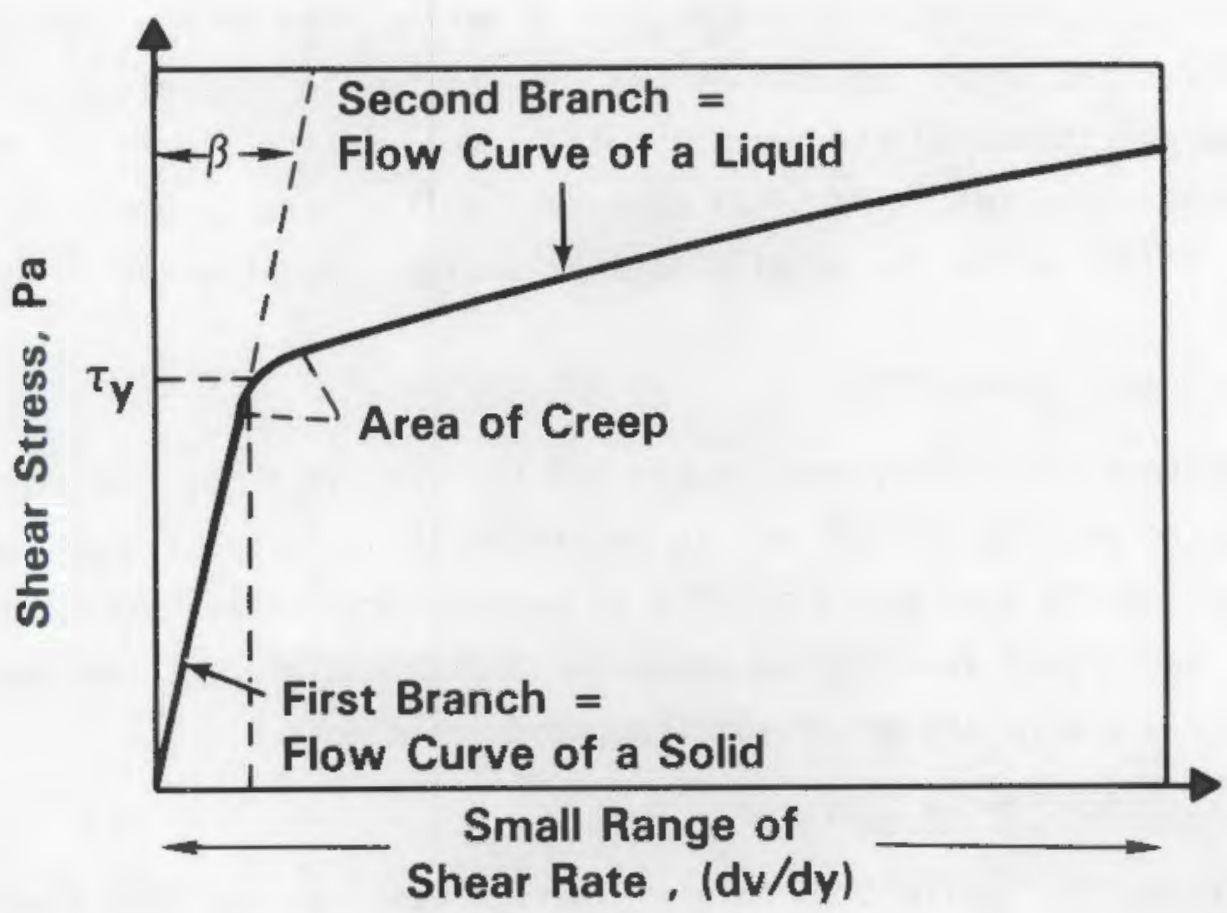

FIGURE 4.2. Flow Curve for a Yield-Pseudoplastic Material

from a solid gel to an easy-flowing liquid may go through a phase of creep, which makes the turning point less clear. Under these conditions the yield point is determined by the crossing point of the tangents on both branches (see Figure 4.2).

Standard laboratory techniques were used to measure physical properties such as pH, density, and total solids content of each NCAW slurry sample (NCAW, NCAW5.5, and NCAW1:1) at 25 and $100^{\circ} \mathrm{C}$. The standard laboratory technique used to measure total dissolved solids was not used because a suitable filter $(0.45 \mu \mathrm{m})$ able to withstand a $\mathrm{pH}$ greater than 13 could not be found.

To determine the total dissolved solids concentration in each slurry, it was assumed that the supernatant contained only dissolved solids. The accuracy of this procedure was affirmed by filtering samples of NCAW through 2.5- m filters. The suspended solids concentration determined by the filtering procedure was in good agreement with the results obtained by the procedure described above. Samples of supernatant of known mass were dried at $105^{\circ} \mathrm{C}$ in a tared 
15-mL plastic beaker until no weight change was noticed over a 24-h period. The weight of the dried supernatant was divided by the initial weight of the sample and multiplied by the percent total liquid in the slurry to obtain the total dissolved solids. The total suspended solids were assumed to be equal to the total solids minus the total dissolved solids concentration.

\subsection{RHEOLOGICAL PROPERTIES}

Laboratory evaluations were conducted to classify three concentrations of NCAW slurries at 25 and $100^{\circ} \mathrm{C}$ and to determine the effects of shear rate and temperature on the apparent viscosity of each slurry. These evaluations provided the background information needed to design and predict the performance of full-scale slurry transport and treatment equipment.

\subsubsection{Classification of Slurries}

An assumption implicit in this evaluation was that the NCAW slurries would be transported at velocities sufficient to prevent particles from settling in the transfer piping. This assumption implies that heterogeneous flow behavior (static bed, moving bed) cannot be tolerated. The objective was to create a pseudohomogeneous or nearly pseudohomogeneous flow regime in transfer piping.

A wide variety of pseudohomogeneous flow regimes are possible (see Section 2.2). The majority of slurries can be treated as if they were yieldpseudoplastic $(Y-P)$ materials. The behavior of these materials can be defined by the following equations (Hershel and Bulkley 1926):

$$
\begin{gathered}
\tau=K\left(\frac{d v}{d y}\right)^{n} \text { when } \tau_{y}=0 \\
\tau=\tau y+K\left(\frac{d v}{d y}\right)^{n} \text { when } \tau_{y}>0
\end{gathered}
$$

where:

$$
\begin{aligned}
\tau & =\text { shear stress, } \mathrm{N} / \mathrm{m}^{2} \text { (Pascal) } \\
\tau_{\mathrm{y}} & =\text { yield stress, } \mathrm{N} / \mathrm{m}^{2} \text { (Pascal) }
\end{aligned}
$$




$$
\begin{aligned}
k & =\text { consistency index, Ns } / \mathrm{m}^{2} \text { (Pascal-sec) } \\
\frac{d v}{d y} & =\text { shear rate in } y \text { direction, } \sec ^{-1} . \\
n & =\text { flow behavior index. }
\end{aligned}
$$

The yield-pseudoplastic model defined by Equations (4) and (5) reduces to the Bingham Plastic model when $n=1$, the pseudoplastic model when $y=0$, and to the Newtonian model when $\tau_{y}=0$ and $n=1$.

A logarithmic plot of Equation (4) for laminar flow data defines the values of $n$ and $k$. The flow behavior index, $n$, is the slope of the line; the intercept of the line at a shear rate of $1 \mathrm{sec}^{-1}$ defines $K$, the consistency index. For a Newtonian fluid, $n$ is equal to one. Yield-pseudoplastic fluids typically have flow behavior indexes less than one. The closer $n$ is to 1 for a pseudoplastic fluid, the more it behaves as a Newtonian fluid.

The rheograms for NCAW at 25 and $100^{\circ} \mathrm{C}$ are depicted in Figure 4.3. These rheograms indicate that NCAW at 25 and $100^{\circ} \mathrm{C}$ is a pseudoplastic material. NCAW

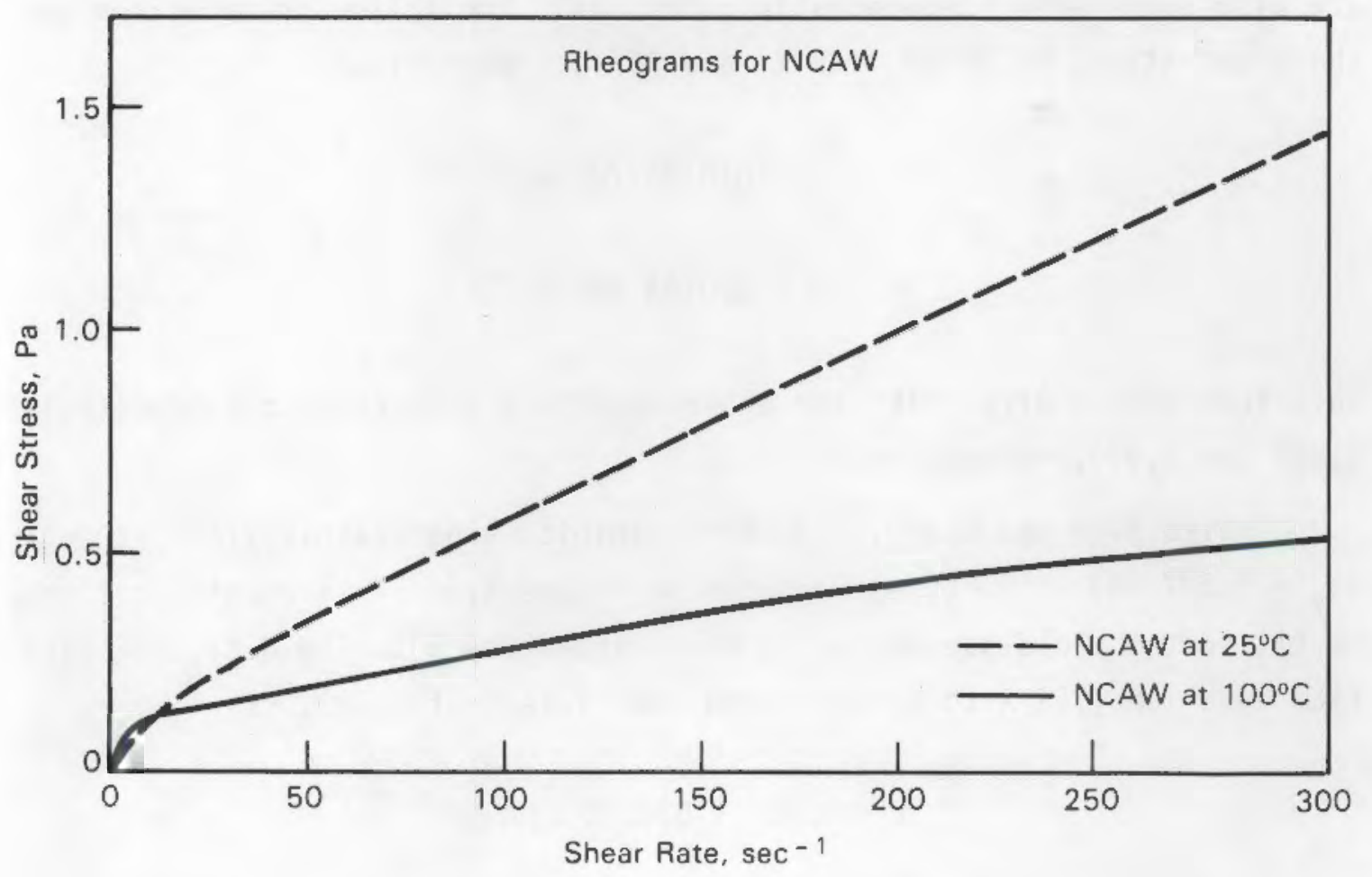

FIGURE 4.3. Rheograms for NCAW at 25 and $100^{\circ} \mathrm{C}$ 
at each temperature does not exhibit a yield strength at low shear rates. The yield stress, $\tau_{y}$, is considered zero even though a small yield point is present on the rheograms since $\tau_{y}$ is less than the standard deviation ( $\pm 8-10$ percent) of the Haake instrument at low shear rates, (McCarthy, Chan and Lokken 1985.) These data were "fit" to the pseudoplastic rheological model (Equation 4 ). Equations (6) and (7) represent the shear stress for NCAW at 25 and $100^{\circ} \mathrm{C}$, respectively.

$$
\begin{aligned}
& \tau=0.0149(\mathrm{dv} / \mathrm{dy})^{0.8} \\
& \tau=0.0211(\mathrm{dv} / \mathrm{dy})^{0.57}
\end{aligned}
$$

Data from both slurries "fit" the above equations with regression coefficients of 0.998 .

The rheograms for NCAW5.5 at 25 and $100^{\circ} \mathrm{C}$ are depicted in Figure 4.4 . These slurries, which exhibit behavior very similar to that displayed by NCAW, are also considered pseudoplastic materials. The following equations describe the shear stress of NCAW5.5 at 25 and $100^{\circ} \mathrm{C}$, respectively.

$$
\begin{aligned}
& \tau=0.0126(d v / d y)^{0.85} \\
& \tau=0.0183(d v / d y)^{0.60}
\end{aligned}
$$

Data from each slurry "fit" the above equations with regression coefficients of 0.999 and 0.997 , respectively.

Un1ike NCAW and NCAW5.5, NCAW1:1 exhibits a noticeable yield strength $\left(\tau_{y}=0.587 \mathrm{~Pa}\right.$ ) at $25^{\circ} \mathrm{C}$, as depicted in Figure 4.5. This rheological data can be fit to the yield-pseudoplastic model (Equation 5). The data in Figure 4.5 fits Equation (10) with a regression coefficient of 0.999 .

$$
\tau=0.587+0.0123(d v / d y)^{0.833}
$$




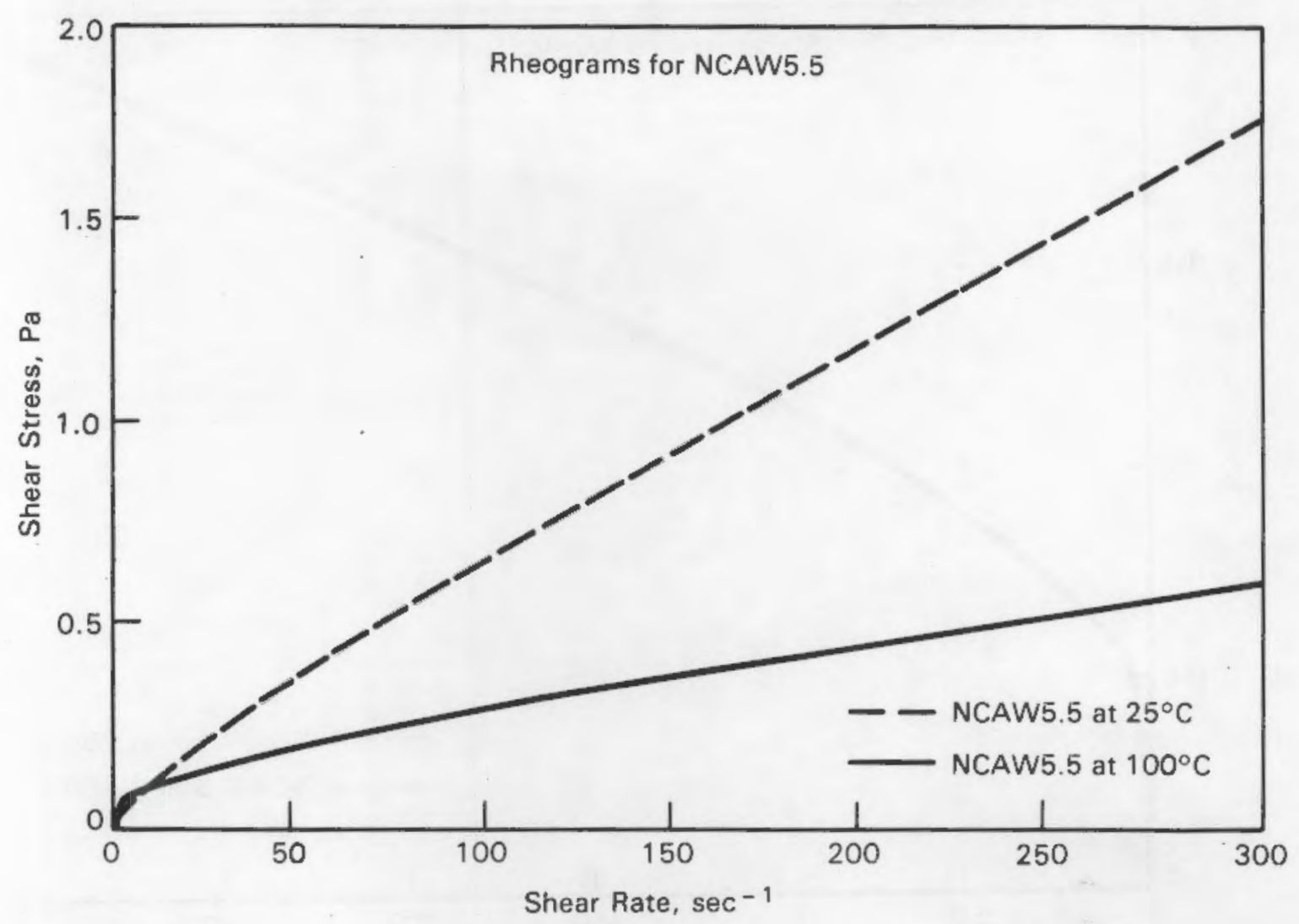

FIGURE 4.4. Rheograms for NCAW5.5 at 25 and $100^{\circ} \mathrm{C}$

At $100^{\circ} \mathrm{C}$, NCAW1:1 appears to have time-dependent properties (see Figure 4.6). A rheogram takes a total of 10 minutes; five minutes for the "up" curve and five minutes for the "down" curve. After ten minutes, NCAW has a lower yield strength than it had initially. This behavior is indicative of shear thinning material. For this report, the "up" curve data will be used because it is the "worst case" data for NCAW1:1 at $100^{\circ} \mathrm{C}$. The yield strength indicated by Figure 4.6 is $1.25 \mathrm{~Pa}$, the flow behavior index is 1.15 , and the consistency index is $0.0006 \mathrm{~Pa}-\mathrm{seC}$. The shear stress for NCAW1:1 at $100^{\circ} \mathrm{C}$ can be fit to the yield pseudoplastic model as follows:

$$
\tau=1.25+0.0006(d v / d y)^{1.15}
$$




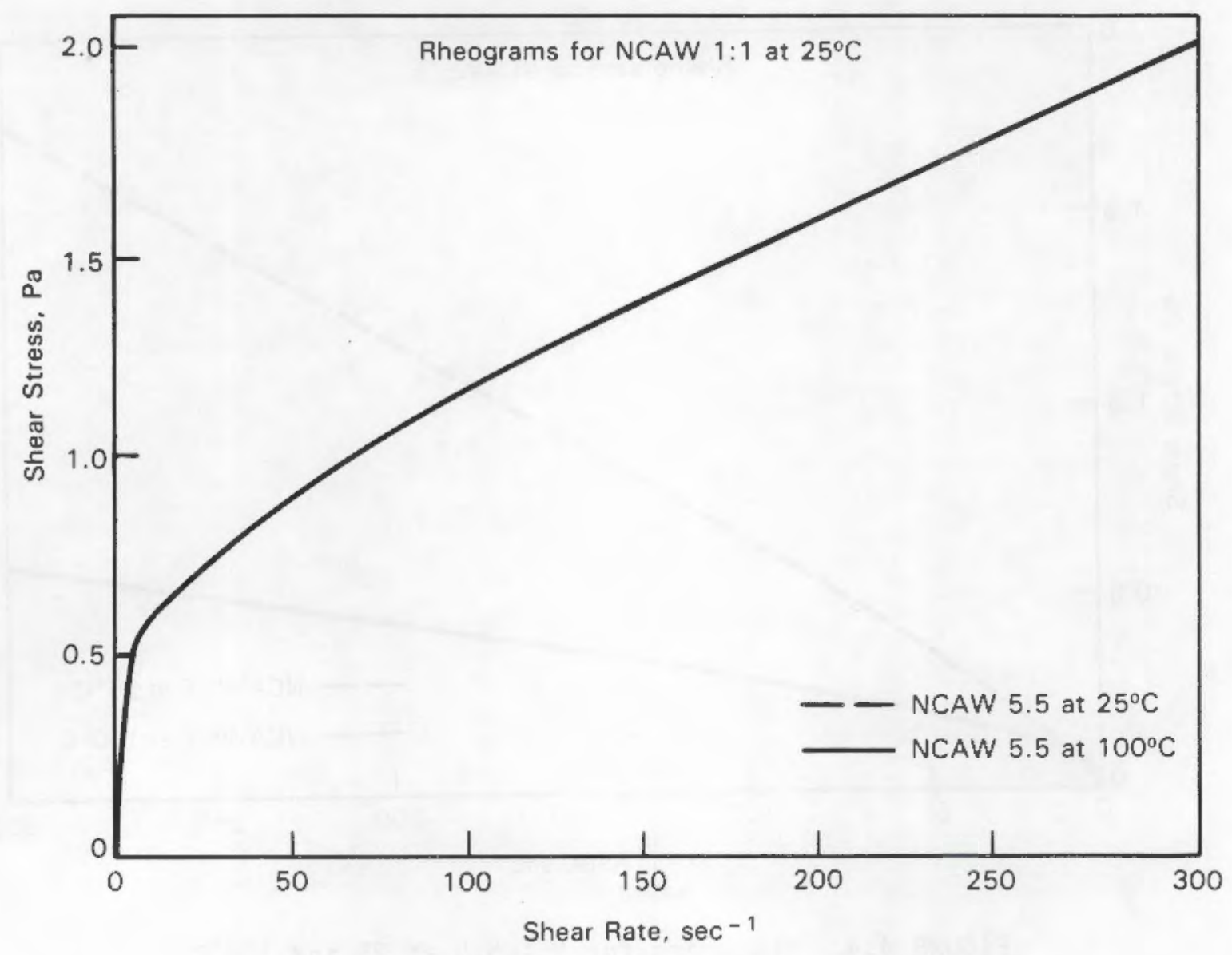

FIGURE 4.5. Rheogram for NCAW $1: 1$ at $25^{\circ} \mathrm{C}$

The "up" curve data in Figure 4.6 "fit" Equation (11) with a regression coefficient of 0.975 .

\subsubsection{Viscosity of NCAW Slurries}

The apparent viscosity of a non-Newtonian fluid is defined as the shear stress divided by the shear rate. The shear stress is evaluated using the yield-pseudoplastic model described in Section 2. A reported apparent viscosity for a non-Newtonian fluid only makes sense if it is accompanied by the shear rate.

The rheological information in Figures 4.3 through 4.6 were used to evaluate the apparent viscosity of each sample and determine the effects of temperatures on viscosity. 


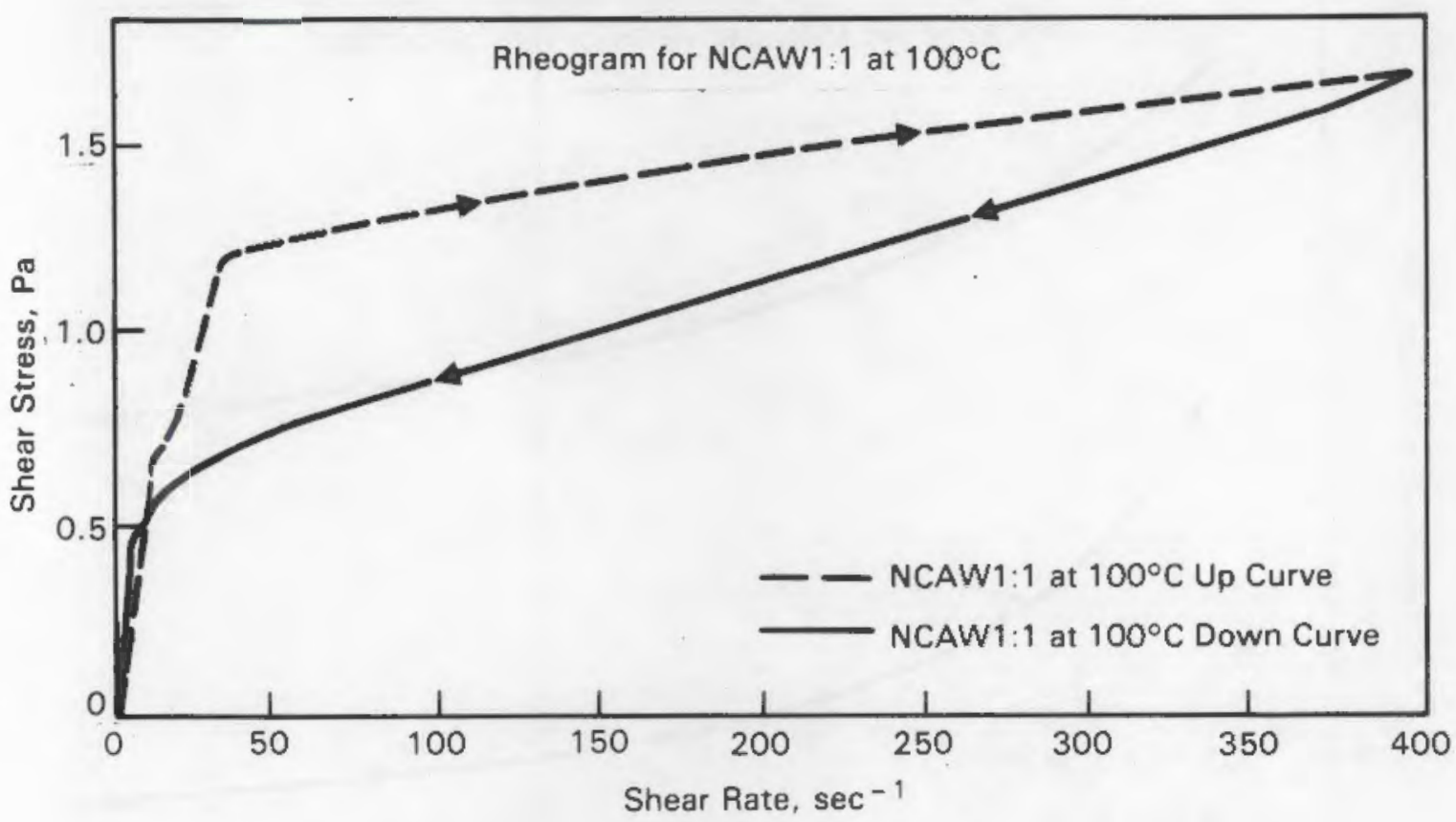

FIGURE 4.6. Rheogram for NCAW1:1 at $100^{\circ} \mathrm{C}$

Plots of viscosity versus shear rate at $25^{\circ} \mathrm{C}$ and $100^{\circ} \mathrm{C}$ for each slurry are presented in Figures 4.7, 4.8, and 4.9. As is typical for all pseudoplastic and yield-pseudoplastic materials, viscosity increased as the shear rate decreased. As expected, viscosity decreased as temperature increased.

NCAW5.5 at 25 and $100^{\circ} \mathrm{C}$ has a slightly higher viscosity than NCAW at 25 and $100^{\circ} \mathrm{C}$ as is expected of a slightly more concentrated slurry. NCAW1:1 has a higher viscosity than NCAW and NCAW5.5 for low shear rates evaluated because it exhibits a yield strength. The yield strength contributes significantly (see Equations 10 and 11) to the shear strength at low values of shear rate.

NCAW1: 1 at $100^{\circ} \mathrm{C}$ has a higher viscosity than NCAW1:1 at $25^{\circ} \mathrm{C}$ at the low shear rates because NCAW1:1 at $100^{\circ} \mathrm{C}$ exhibits a higher yield strength. As the shear rate increases, the viscosity of the higher temperature slurry decreases to values below the lower-temperature slurry. 


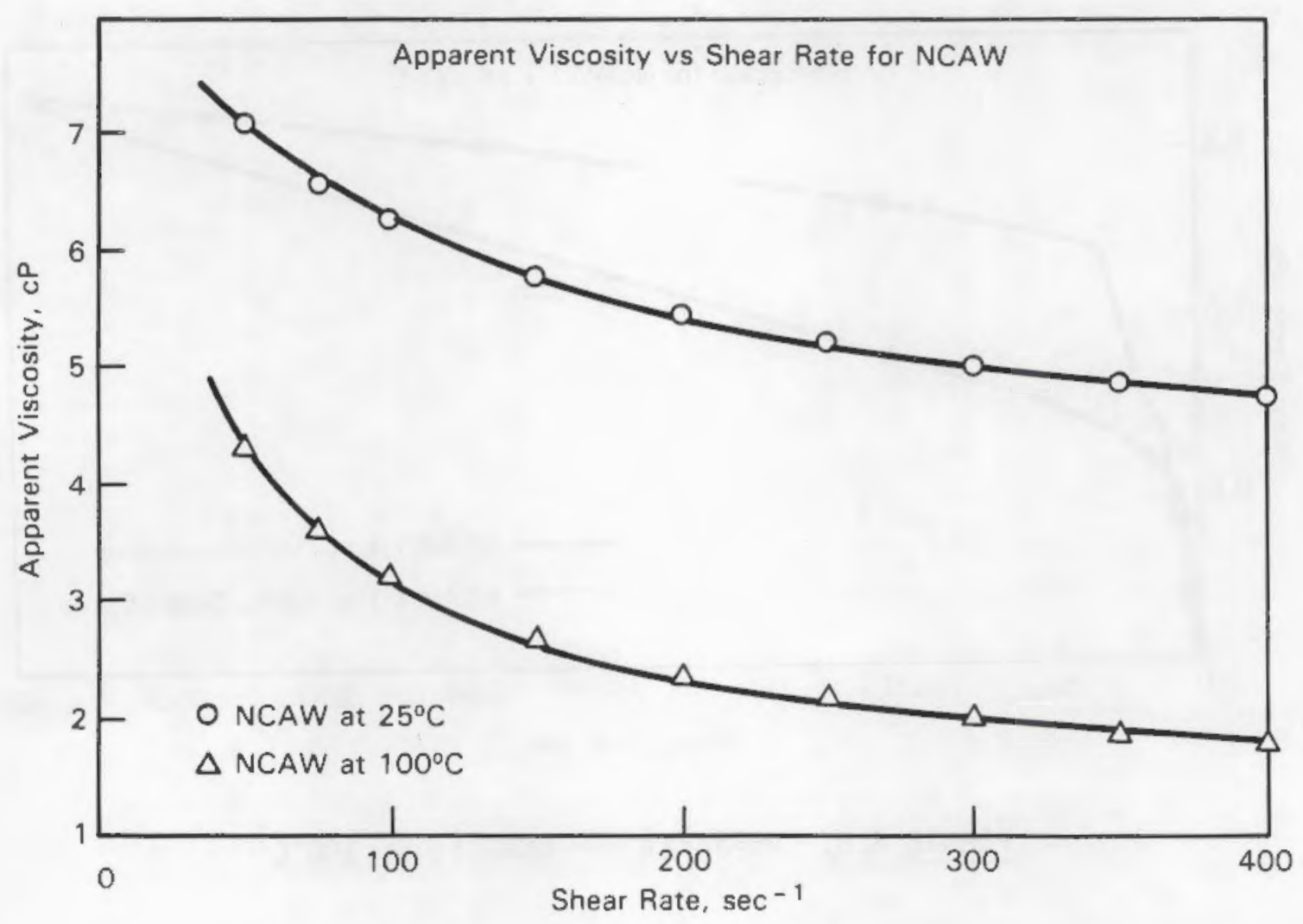

FIGURE 4.7. Apparent Viscosity versus Shear Rate for NCAW at 25 and $100^{\circ} \mathrm{C}$

The rate of shear for yield-pseudoplastic and pseudoplastic materials in a pipe is proportional to the velocity of the fluid and the diameter of the pipe. For flow at 50 and $75 \mathrm{gpm}$ through a $3 \mathrm{in}$. diameter pipe, the rate of shear is 68 and $102 \mathrm{sec}^{-1}$, respectively.

\subsection{PHYSICAL PROPERTIES}

Standard laboratory techniques were used to measure physical properties such as $\mathrm{pH}$, slurry density, total solids content, and settling rates of each NCAW, NCAW5.5, and NCAW1: 1 sample at 25 and $100^{\circ} \mathrm{C}$. The standard laboratory technique used to measure total dissolved solids was not used because a suitable filter (0.45-micron) able to withstand a pH greater than 13 could not be found. 


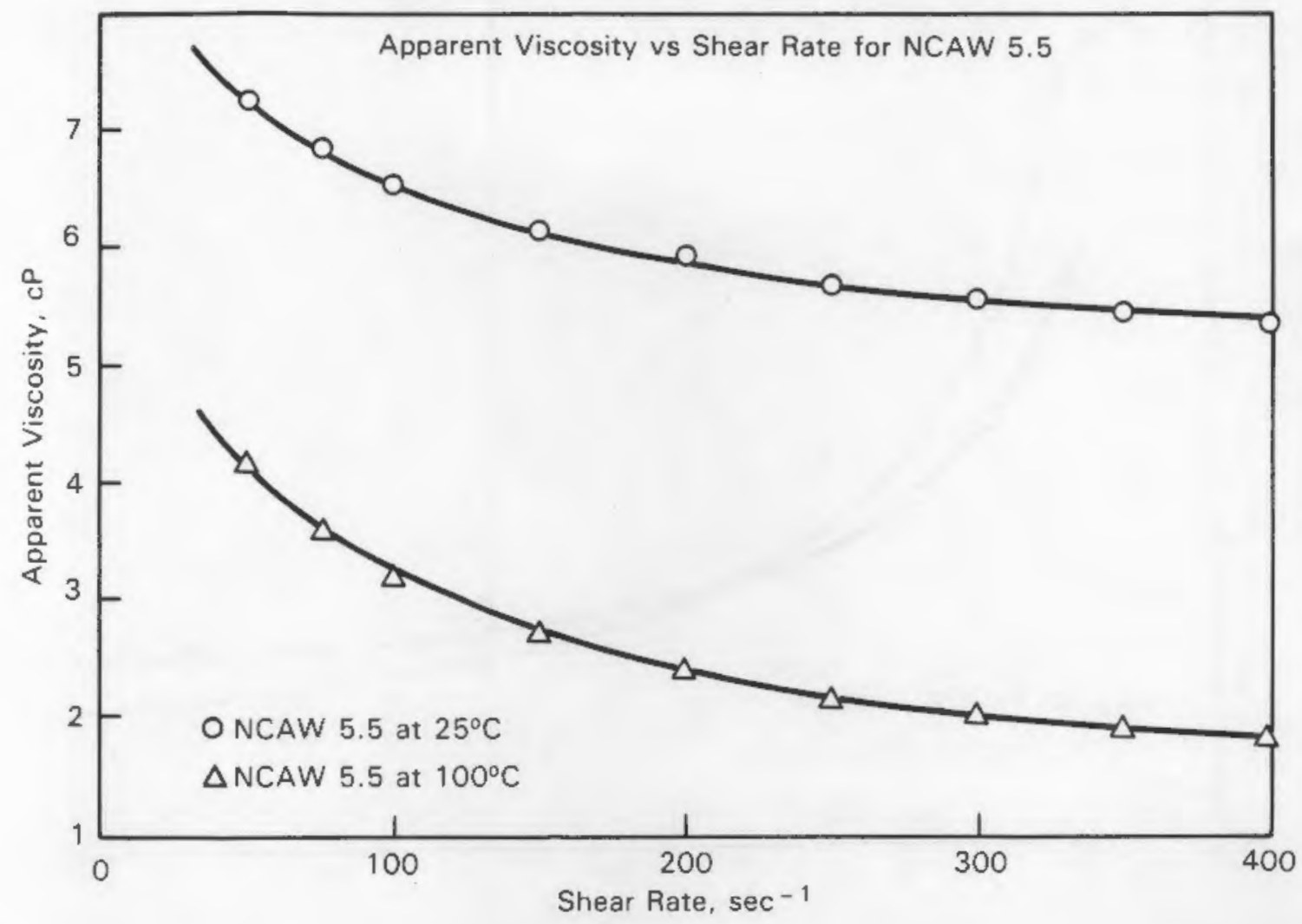

FIGURE 4.8. Apparent Viscosity versus Shear Rate for NCAW5.5 at 25 and $100^{\circ} \mathrm{C}$

To determine the total dissolved solids, it was assumed that the supernatants contain only dissolved solids. Samples of supernatant of known mass were dried at $105^{\circ} \mathrm{C}$ in a tared $15-\mathrm{mL}$ plastic beaker until no weight change was noticed over a 24-h period. The weight of the dried supernatant was divided by the initial weight of the sample and multiplied by the percent total liquid in the slurry to obtain the total dissolved solids. The total suspended solids were assumed to be equal to the total solids minus the total dissolved solids concentration.

An attempt was made to quantitatively determine the resuspendability of NCAW slurry. Three samples of each slurry for each temperature were placed in graduated cylinders and allowed to settle for several days. The cylinders were inverted then returned to the upright condition. The inversions were repeated until all the solids were resuspended. The number of inversions required to resuspend the solids is referred to as the "resuspendability index." 


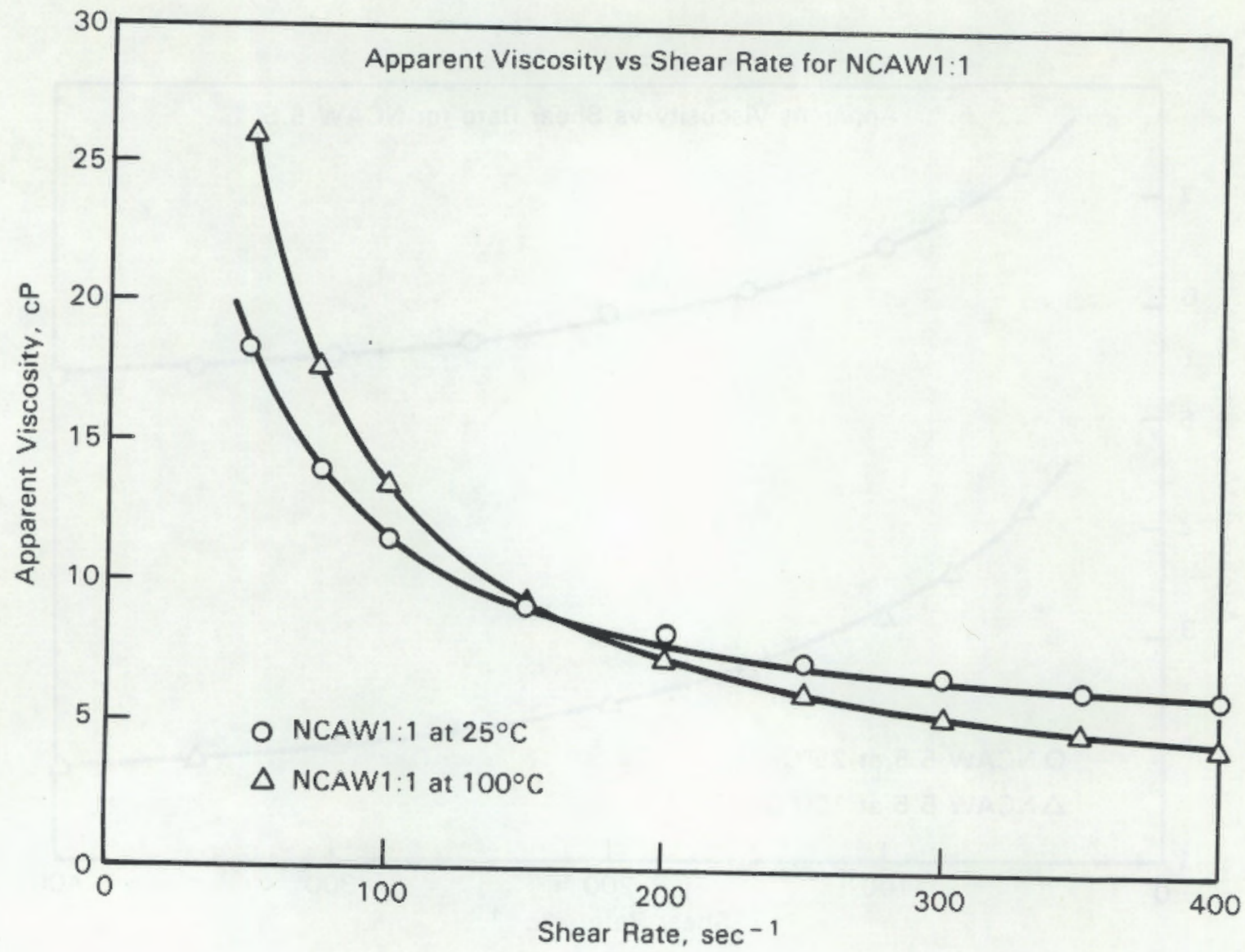

FIGURE 4.9. Apparent Viscosity versus Shear Rate for NCAW1:1 at 25 and $100^{\circ} \mathrm{C}$

\subsubsection{NCAW}

The $\mathrm{pH}$, density, and solids weight distribution results obtained for each sample of NCAW at 25 and $100^{\circ} \mathrm{C}$ are summarized in Table 4.1. Reliable pH data are difficult to obtain when the $\mathrm{pH}$ level nears 14. Several calibrated $\mathrm{pH}$ meters were used to assess the $\mathrm{pH}$ of NCAW at $25^{\circ} \mathrm{C}$. Each of these meters indicated a $\mathrm{pH}>13$, and this level of $\mathrm{pH}$ was included in Table 4.1. At a temperature of $100^{\circ} \mathrm{C}$, and $\mathrm{pH}$ levels near 14 , it is not practical to evaluate a specific level of $\mathrm{pH}$. In this case, a specific value for $\mathrm{pH}$ was not included in Table 4.1.

The total solids concentration represents approximately $30 \mathrm{wt} \%$ of the slurry. Most of the total solids are dissolved solids. The calculated value of suspended solids concentration decreased as temperature increased. This 
TABLE 4.1. Physical Properties of Neutralized Current Acid Waste (NCAW) at 25 and $100^{\circ} \mathrm{C}$

\begin{tabular}{|c|c|c|c|c|c|c|c|c|c|c|}
\hline \multirow[b]{3}{*}{ Property } & \multicolumn{3}{|c|}{$25^{\circ} \mathrm{C}$} & \multirow[b]{3}{*}{$\bar{x}$} & \multirow[b]{3}{*}{$S$} & \multicolumn{5}{|c|}{$100^{\circ} \mathrm{C}$} \\
\hline & \multicolumn{3}{|c|}{ Sample Number } & & & San & ple Nun & ber & \multirow[b]{2}{*}{$\bar{X}$} & \multirow[b]{2}{*}{$\mathrm{S}$} \\
\hline & $\# 1$ & $\# 3$ & $\# 5$ & & & $\# 2$ & $\# 4$ & $\# 6$ & & \\
\hline $\mathrm{pH}$ & $>13$ & $>13$ & $>13$ & & & - & - & - & & \\
\hline Density $(\mathrm{g} / \mathrm{cc})$ & 1.26 & 1.27 & 1.27 & 1.27 & 0.01 & 1.26 & 1.26 & 1.26 & 1.26 & 0 \\
\hline Total solids (wt\%) & 30.5 & 30.4 & 30.2 & 30.37 & 0.15 & 31.1 & 30.8 & 30.6 & 30.83 & 0.25 \\
\hline $\begin{array}{l}\text { Total dissolved } \\
\text { solids (wt) }\end{array}$ & 28.4 & 28.2 & 28.8 & 28.47 & 0.31 & 30.8 & 30.1 & 29.9 & 30.27 & 0.47 \\
\hline $\begin{array}{l}\text { Total suspended } \\
\text { solids (wt\%) }\end{array}$ & 2.1 & 2.2 & 1.4 & 1.90 & 0.44 & 0.3 & 0.7 & 0.7 & 0.57 & 0.23 \\
\hline
\end{tabular}

$\overline{\bar{x}}=$ Mean value.

$S=$ Standard deviation. 
decrease was probably due to dissolution of some of the solids in the slurry as the temperature was increased.

To determine the suspended solids settling rate, samples of simulated NCAW were placed in 100-mL graduated cylinders, shaken, then allowed to settle. The level of the interface between the solids and clear liquid was recorded as it descended in the cylinder. This interface is referred to as the "trailing edge." The rate of descent of the fastest falling particles, the "leading edge," could not be determined because of the opaqueness of the fluid. Plots of interface height versus time were prepared for each sample. Figure 4.10 plots the average settling rate of three samples at each temperature.

The average settling rate for the linear portion of the curve for three samples of NCAW is $0.55 \mathrm{~cm} / \mathrm{h}$ at $25^{\circ} \mathrm{C}$ and $4.50 \mathrm{~cm} / \mathrm{h}$ at $100^{\circ} \mathrm{C}$. These data, along

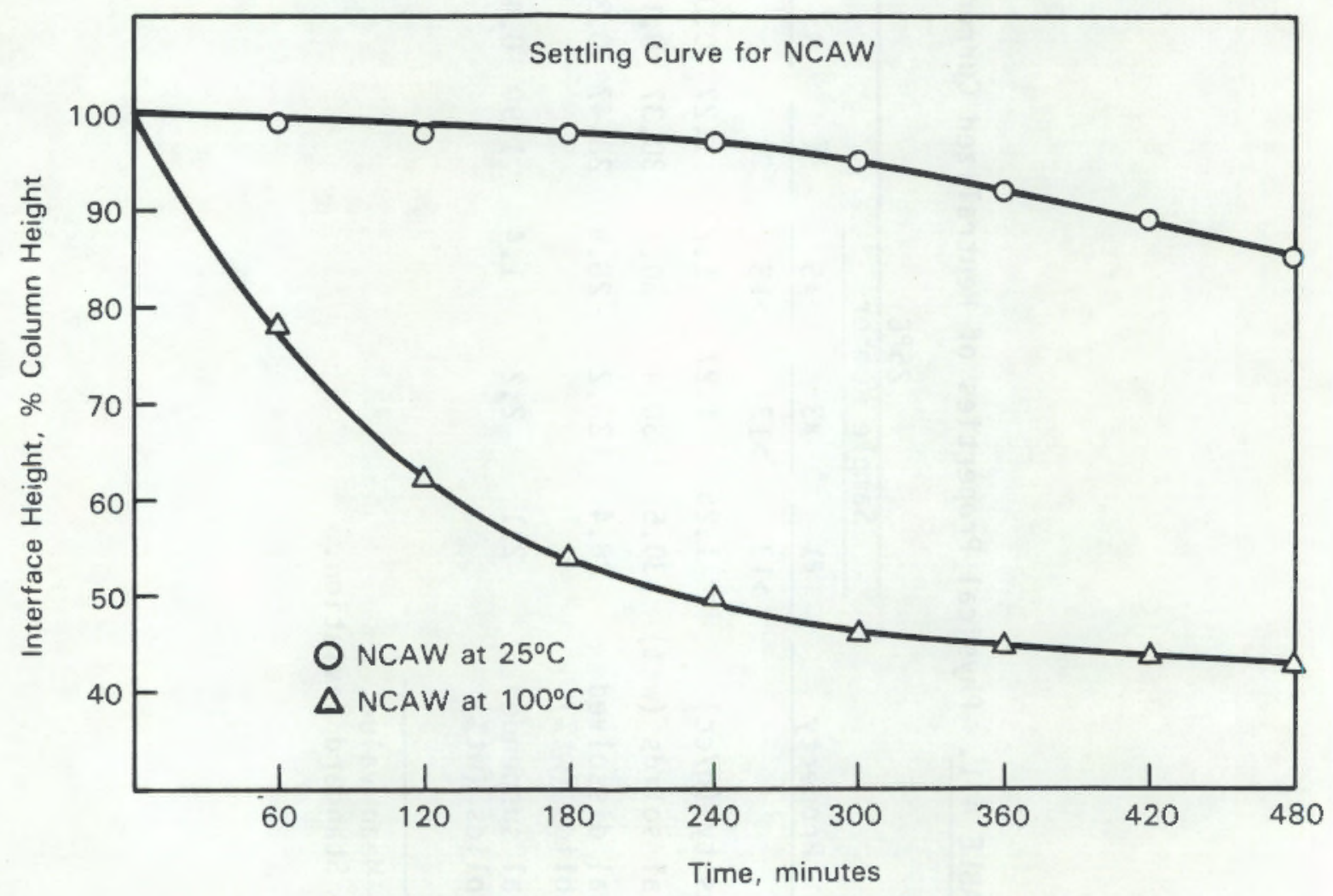

FIGURE 4.10. NCAW Suspended Solids Settling Curve at 25 and $100^{\circ} \mathrm{C}$. These curves represent the average settling rate of three laboratory samples at each temperature. 
with the standard deviation and ultimate settled solids height in the graduated cylinder, are presented in Table 4.2. The average vol\% settled solids at $25^{\circ} \mathrm{C}$ for the simulated NCAW was $40 \%$ whereas the NCAW in tank $101 A 2$ is expected to have a settled solids volume of $20 \%$. At higher temperatures, the NCAW solids tended to settle more rapidly. For example, sample \#3 had a settling rate of $5.13 \mathrm{~cm} / \mathrm{h}$ at $100^{\circ} \mathrm{C}$, nearly nine times as high as the settling rate achieved at $25^{\circ} \mathrm{C}$. However, even at the higher temperatures, these slow settling rates are not a primary concern in the design of pump-pipe networks.

To determine the resuspendability of NCAW, three samples of slurry at $25^{\circ} \mathrm{C}$ and three samples at $100^{\circ} \mathrm{C}$ were placed in graduated cylinders and allowed to settle until little change was noticed in the height of the liquid-solids interface. At that time, the interface height was recorded. The cylinders were inverted then returned to the upright condition. The inversions were repeated until all settled solids were suspended. The number of inversions to resuspend the solids in the slurry and the ultimate solids height for each sample are summarized in Table 4.2 .

Simulated NCAW at $25^{\circ} \mathrm{C}$ was resuspended after two inversions. A total of nine inversions was required to resuspend NCAW at $100^{\circ} \mathrm{C}$. This increase in the resuspendability index is related to the change in the physical-chemical properties (particle size, shape, surface charge, chemical compounds) of the slurry that were caused by the increase in temperature. An evaluation of the specific nature of these changes was beyond the scope of this work.

\subsubsection{Concentrated NCAW (NCAW5.5)}

NCAW5.5 was prepared by evaporating the water in NCAW supernatant until a $5.5-M$ concentration of sodium was achieved. This corresponded to an $8.7 \%$ reduction in volume of NCAW. Table 4.3 summarized the $\mathrm{pH}$, density and solids weight distribution of these samples of NCAW5.5 at 25 and $100^{\circ} \mathrm{C}$. Because of this volume reduction, the density and total solids concentration of NCAW5.5 are higher than corresponding values for NCAW.

NCAW5.5 at $25^{\circ} \mathrm{C}$ exhibited settling rate values $27 \%$ higher than those observed for NCAW slurry at $25^{\circ} \mathrm{C}$. The settling rates observed at $100^{\circ} \mathrm{C}$ were similar to those observed with NCÁW. The average settling rate curve for the 
TABLE 4.2. Settling Rates and Resuspendability Index for NCAW at 25 and $100^{\circ} \mathrm{C}$

\begin{tabular}{|c|c|c|c|c|c|c|c|c|c|c|}
\hline \multirow[b]{3}{*}{ Property } & \multicolumn{5}{|c|}{$25^{\circ} \mathrm{C}$} & \multicolumn{5}{|c|}{$100^{\circ} \mathrm{C}$} \\
\hline & \multicolumn{3}{|c|}{ Sample Number } & \multirow[b]{2}{*}{$\bar{x}$} & \multirow[b]{2}{*}{$s$} & \multicolumn{3}{|c|}{ Sample Number } & \multirow[b]{2}{*}{$\bar{x}$} & \multirow[b]{2}{*}{$\mathrm{S}$} \\
\hline & $\# 1$ & $\# 3$ & $\# 5$ & & & $\# 2$ & $\# 4$ & $\# 6$ & & \\
\hline $\begin{array}{l}\text { Settling rate } \\
(\mathrm{cm} / \mathrm{hr})\end{array}$ & 0.58 & 0.46 & 0.62 & 0.55 & 0.08 & 5.13 & 3.61 & 4.76 & 4.50 & 0.79 \\
\hline $\begin{array}{l}\text { Ultimate settled } \\
\text { solid height } \\
\text { ( } \% \text { column height) }\end{array}$ & 41 & 40 & 38 & 40.5 & .71 & 35 & 31 & 28 & 33 & 2.83 \\
\hline $\begin{array}{l}\text { Resuspendability } \\
\text { index }\end{array}$ & 2 & 2 & 4 & - & - & 11 & 9 & 20 & - & - \\
\hline $\begin{array}{l}\text { Number of settling } \\
\text { days }\end{array}$ & 7 & 7 & 12 & - & - & 2 & 7 & 12 & - & - \\
\hline
\end{tabular}


TABLE 4.3. Physical Properties of NCAW5.5 at 25 and $100^{\circ} \mathrm{C}$

\begin{tabular}{|c|c|c|c|c|c|c|c|c|c|c|}
\hline \multirow{4}{*}{ Property } & \multicolumn{5}{|c|}{$25^{\circ} \mathrm{C}$} & \multirow{2}{*}{\multicolumn{5}{|c|}{$100^{\circ} \mathrm{C}$}} \\
\hline & \multicolumn{3}{|c|}{ Sample Number } & \multirow[b]{2}{*}{$\overrightarrow{\mathbf{X}}$} & \multirow[b]{2}{*}{$S$} & Sample Number & & & & \multirow[b]{2}{*}{$\mathrm{S}$} \\
\hline & $\# 7$ & \#9 & $\# 11$ & & & $\# 8$ & $\# 10$ & \#12 & $\bar{x}$ & \\
\hline & $>13$ & $>13$ & $>13$ & - & - & - & - & - & - & - \\
\hline Density $(g / c c)$ & 1.31 & 1.30 & 1.30 & 1.303 & 0.006 & 1.29 & 1.29 & 1.28 & 1.287 & 0.006 \\
\hline Total solids (wt\%) & 32.8 & 32.8 & 32.6 & 32.73 & 0.115 & 33.4 & 33.2 & 33.1 & 33.23 & 0.153 \\
\hline $\begin{array}{l}\text { Total dissolved } \\
\text { solids (wt\%) }\end{array}$ & 30.4 & 30.4 & 30.5 & 30.43 & 0.058 & 32.8 & 32.1 & 32.6 & 32.5 & 0.361 \\
\hline $\begin{array}{l}\text { Total suspended } \\
\text { solids (wt\%) }\end{array}$ & 2.4 & 2.4 & 2.1 & 2.3 & 0.173 & 0.6 & 1.1 & 0.5 & 0.73 & 0.321 \\
\hline
\end{tabular}

$\overline{\bar{X}}=$ Mean value.

$S=$ Standard deviation. 
three samples of NCAW5.5 evaluated at each temperature are presented in Figure 4.11. Table 4.4 lists the individual sample settling rates.

Simulated NCAW5.5 at $25^{\circ} \mathrm{C}$ was resuspended after four inversions when it had settled for seven days. It took 15 inversions to resuspend NCAW5.5 at $100^{\circ} \mathrm{C}$. As with NCAW, the increase in the resuspendability index is related to the changes in the physical-chemical properties of the slurry that were induced by the increase in temperature.

\subsubsection{NCAW $1: 1$}

NCAW1:1 was prepared by adding one volume of water to one volume of NCAW settled solids. The density, total solids, and dissolved solids concentration of NCAW1:1 (Table 4.5) were less than the values displayed by NCAW and NCAW5.5 (Table 4.1 and Table 4.3, respectively). This result was expected. The bulk of the supernatant in NCAW, which contains the majority of the solids in the

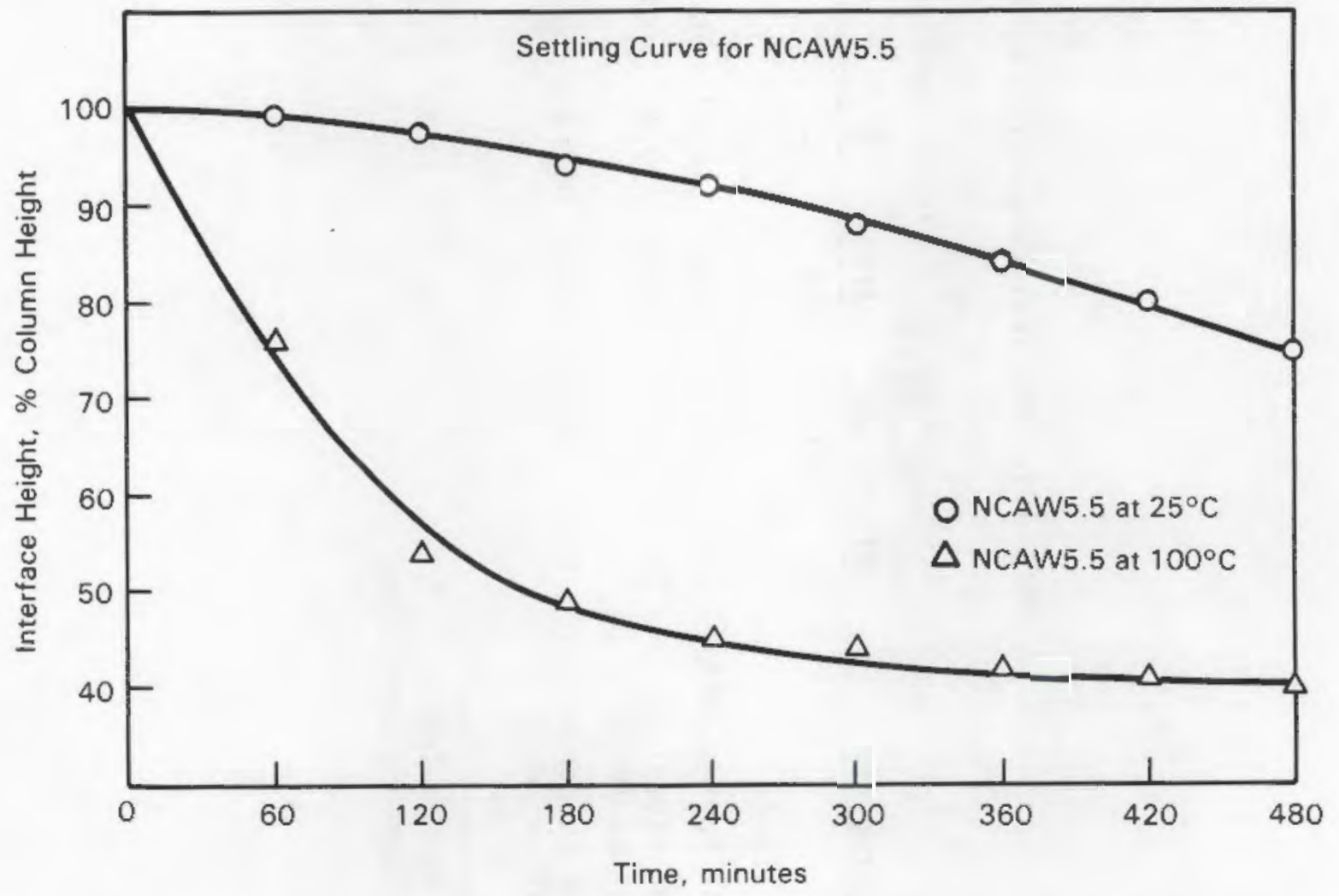

FIGURE 4.11. NCAW5.5 Suspended Solids Settling Curve at 25 and $100^{\circ} \mathrm{C}$. These curves represent the average settling rate of three laboratory samples evaluated at each temperature. 
TABLE 4.4. Settling Rates and Resuspendability Index for NCAW5.5 at 25 and $100^{\circ} \mathrm{C}$

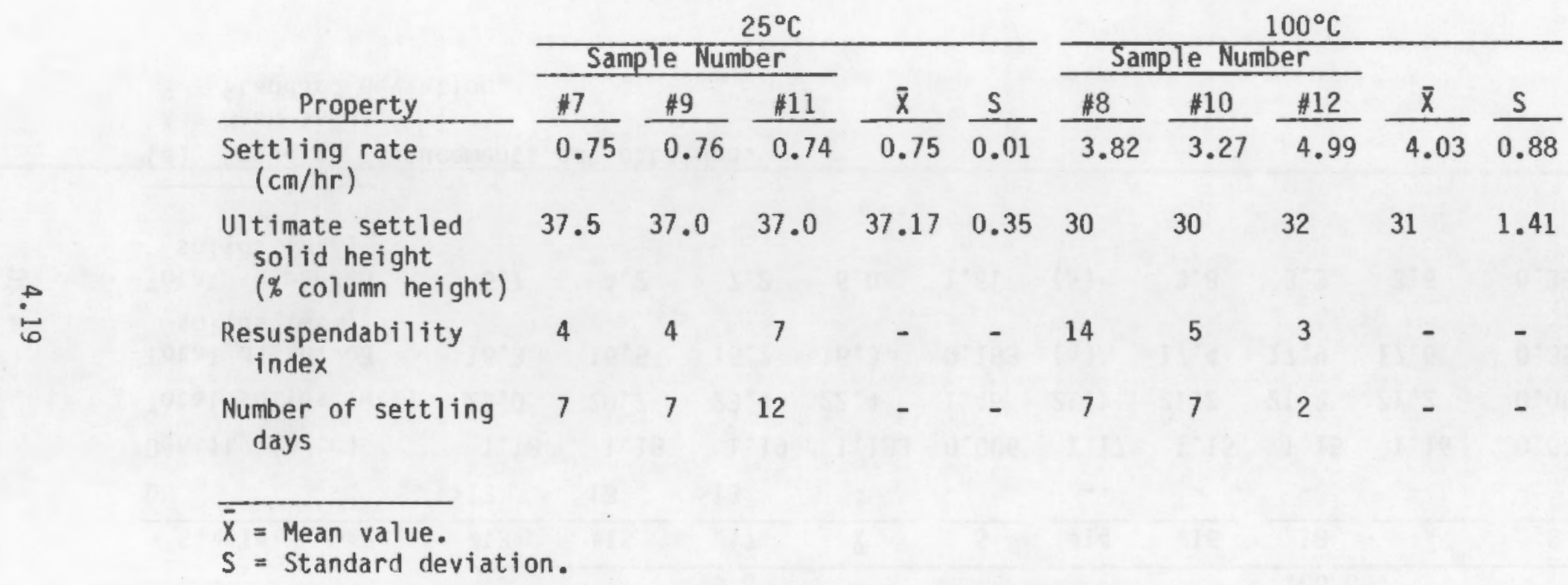


TABLE 4.5. Physical Properties of NCAW1.1 at 25 and $100^{\circ} \mathrm{C}$

\begin{tabular}{|c|c|c|c|c|c|c|c|c|c|c|}
\hline \multirow[b]{2}{*}{ Sample Number } & \multicolumn{5}{|c|}{$25^{\circ} \mathrm{C}$} & \multicolumn{5}{|c|}{$100^{\circ} \mathrm{C}$} \\
\hline & $\# 13$ & $\# 15$ & $\# 17$ & $\bar{x}$ & $\mathrm{~S}$ & $\# 14$ & $\# 16$ & $\# 18$ & 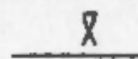 & $\mathrm{S}$ \\
\hline $\mathrm{pH}$ & $>13$ & $>13$ & $>13$ & - & - & - & - & - & - & - \\
\hline Density $(g / c c)$ & 1.18 & 1.18 & 1.19 & 1.183 & 0.006 & 1.17 & 1.15 & 1.15 & 1.16 & 0.012 \\
\hline Total solids (wt\%) & 23.0 & 20.7 & 23.4 & 22.4 & 1.46 & 21.1 & 21.2 & 21.2 & 21.2 & 0.058 \\
\hline $\begin{array}{l}\text { Total dissolved } \\
\text { solids (wt\%) }\end{array}$ & 16.3 & 16.5 & 16.2 & 16.3 & 0.153 & (a) & 17.4 & 17.9 & 17.6 & 0.354 \\
\hline $\begin{array}{l}\text { Total suspended } \\
\text { solids (wt\%) }\end{array}$ & 6.7 & 4.2 & 7.2 & 6.0 & 1.61 & (a) & 3.8 & 3.3 & 3.6 & 0.354 \\
\hline
\end{tabular}

\footnotetext{
(a) Accurate measurements not obtained.

$\bar{X}=$ Mean value.

$S=$ Standard deviation.
} 
slurry in the form of dissolved solids, was removed during the preparation of NCAW1:1. This solids-laden supernatant was replaced by tap water.

NCAW $1: 1$ at $25^{\circ} \mathrm{C}$ settled $64 \%$ faster than NCAW at $25^{\circ} \mathrm{C}$. NCAW1:1 at $100^{\circ} \mathrm{C}$ settled $83 \%$ slower than NCAW at $100^{\circ} \mathrm{C}$. Table 4.6 summarizes the settling rates for each sample at the two temperatures. Figure 4.12 depicts the settling curves for the average settling rates obtained for the three samples evaluated at 25 and $100^{\circ} \mathrm{C}$.

Simulated NCAW1:1 at $25^{\circ} \mathrm{C}$ was resuspended after 10 inversions. NCAW1:1 at $100^{\circ} \mathrm{C}$ required 18 inversions to resuspend all the settled solids (Table 4.6). These resuspension increases are higher than the corresponding increases for NCAW (Table 4.2) and NCAW5.5 (Table 4.4). 
TABLE 4.6. Settling Rates and Resuspendability Index for NCAW1:1 at 25 and $100^{\circ} \mathrm{C}$

\begin{tabular}{|c|c|c|c|c|c|c|c|c|c|c|}
\hline \multirow[b]{2}{*}{ Sample Number } & \multicolumn{5}{|c|}{$25^{\circ} \mathrm{C}$} & \multicolumn{5}{|c|}{$100^{\circ} \mathrm{C}$} \\
\hline & $\# 13$ & $\# 15$ & $\# 17$ & $\bar{x}$ & $\mathrm{~s}$ & $\# 14$ & $\# 16$ & $\# 18$ & $\bar{x}$ & $\mathrm{~s}$ \\
\hline $\begin{array}{l}\text { Settling rate } \\
(\mathrm{cm} / \mathrm{hr})\end{array}$ & 1.45 & 0.20 & 0.89 & 0.85 & 0.63 & 4.20 & 1.67 & 1.47 & 2.45 & 1.52 \\
\hline $\begin{array}{l}\text { U1timate settled } \\
\text { solid height } \\
\text { ( } \% \text { column height) }\end{array}$ & 62 & 73 & 65 & 69.0 & 5.7 & 55 & 65 & 66 & 65.5 & 0.71 \\
\hline $\begin{array}{l}\text { Resuspendability } \\
\text { index }\end{array}$ & 10 & 3 & 3 & - & - & 18 & 5 & 10 & - & - \\
\hline $\begin{array}{l}\text { Number of settling } \\
\text { days }\end{array}$ & 7 & 2 & 2 & - & - & 7 & 2 & 2 & - & - \\
\hline
\end{tabular}




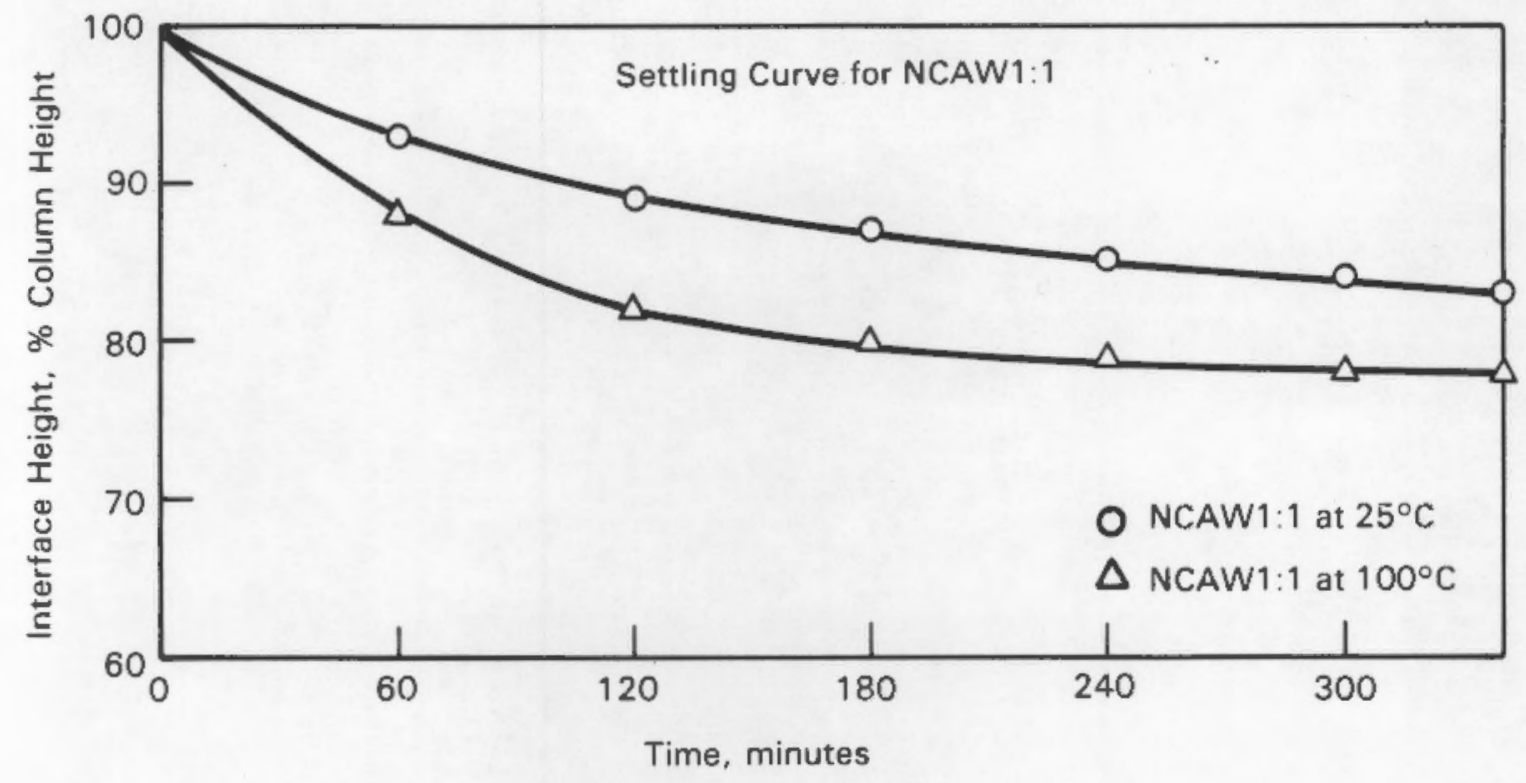

FIGURE 4.12. NCAW1:1 Suspended Solids Settling Curve at 25 and $100^{\circ} \mathrm{C}$. These curves represent the average settling rates of three laboratory samples evaluated at each temperature. 



\subsection{RHEOLOGICAL MOOELS FOR FLOW IN PIPES}

A wide variety of empirical equations have been developed to model the flow behavior of non-Newtonian pseudohomogeneous suspensions (Govier and Aziz 1982, Skelland 1967, Lazarus 1980). A few theoretically consistent models have been developed for the flow of pseudoplastic, and yield-pseudoplastic materials in circular pipes. These models permit the calculation of Reynolds numbers, critical velocities, and line pressure drops for these non-Newtonian fluids. This section will describe the theoretical models used to scale up laboratory rheological data to predict the performance of full-scale pump-pipe networks.

\subsection{PSEUDOPLASTIC FLUIDS}

The relationship between shear stress and rate of shear for pseudoplastic materials (see Figure 2.2) was defined as:

$$
\tau=K\left(\frac{d V}{d y}\right)^{n}
$$

For the incompressible flow of time-independent pseudoplastic materials in circular pipes (Metzner and Reed 1955), Equation (12) reduces to:

$$
\tau_{w}=\frac{D \Delta P}{4 L}=K^{\prime}\left(\frac{8 V}{D}\right)^{n}
$$

where: $\tau_{w}=$ shear stress at wall, $1 b_{f} / \mathrm{ft}^{2}$

$\mathrm{n}=$ flow behavior index

$K^{\prime}=$ consistency index $1 b_{f} s e c / f t^{2}$

$D=$ diameter, $\mathrm{ft}$

$V=$ velocity, ft/sec

$\Delta \mathrm{P}=$ pressure $\mathrm{drop} 1 \mathrm{~b}_{\mathrm{f}} / \mathrm{ft}^{2}$

$L=$ equivalent length, ft 
The graphical procedures described in Section 4.2.1 are used to determine values of $K$ and $n$. The consistency index $K^{\prime}$ is applicable to the flow of fluids in circular pipe. It is related to the generic consistency index $k$ by:

$$
K^{\prime}=K\left[\frac{3 n+1}{4 n}\right]^{n}
$$

The generic consistency index, $K$, is independent of the type of apparatus in which the measurements were made. The rotational viscometer used during the laboratory evaluations described in Section 4 yields values of the generic consistency index $\mathrm{K}$.

The Fanning friction factor is defined as:

$$
f=\frac{D \Delta P}{4 L} / \frac{\rho v^{2}}{2 g_{c}}
$$

Metzner and Reed substituted the right side of Equation (13) into Equation (15) and obtained:

$$
\begin{gathered}
f=\frac{16 \gamma}{D^{n} v^{2-n_{\rho}}} \\
\text { where } \gamma=g_{c} K^{\prime} 8^{n-1}
\end{gathered}
$$

They then let $f=16 / R e$, for the laminar flow of non-Newtonian fluids, and rearranged Equation (16) to yield a Reynolds number,

$$
(\mathrm{Re})_{M-R}=\frac{D^{n} v^{2-n} \rho}{\gamma} \text {, }
$$


that applies to the pseudohomogeneous flow of time-independent pseudoplastic materials in circular tubes. For Newtonian fluids ( $\left.n=1, K^{\prime}=\mu \AA \quad{ }^{\prime} \gamma=\mu\right)$ Equation (18) reduces to the traditional Newtonian Reynolds number.

Metzner and Reed believed that all pseudoplastic materials would follow the usual $f$ versus Re relationship in the laminar region when Equation (18) was used to calculate Re, as long as no "slip" at the wall of the pipe occurred. The "no-slip" assumption is implicit in the development of Equation (15). Metzner and Reed used Equation (18) to calculate Reynolds numbers in the turbulent region as well. They defined the onset of turbulence as the point at which $f$ just declines below about 0.008 or when $(R e)_{M-R}$ reaches a value of 2000-2500.

Metzner and Dodge (1959) extended Metzner's earlier work to correlate friction factors and Reynolds numbers in the turbulent flow regime. They determined that $f$ versus $(R e)_{M-R}$ data for a wide variety of time-independent, inelastic pseudoplastic slurries fit an empirical model:

$$
\frac{1}{\sqrt{f}}=\frac{4.0}{n^{0.75}} \log (\operatorname{Re})_{M-R} f^{(1-n / 2)}-\frac{0.40}{n^{1.2}}
$$

This model is depicted in graphical form on Figure 5.1. This figure implies that the onset of turbulence occurs at values of $(R e)_{M-R}$ greater than 2100 , and tends to occur at increasing values as the value of $n$ declines. Metzner and Dodge postulate that fluid "slip" at the wall of the pipe might be one reason for the reduced values of $f$ that they experienced.

The use of Equation (18) to calculate Reynolds numbers in the turbulent flow range has been challenged recently (Hanks 1979). Hanks points out that Equation (18) is only valid for laminar flow of true pseudoplastic materials (no yield stress, $n<1$ ) in circular pipes with linear shear stress distributions. The Metzner and Reed approach was pursued here since NCAW and NCAW5.5 are pseudoplastic materials (Section 4). 


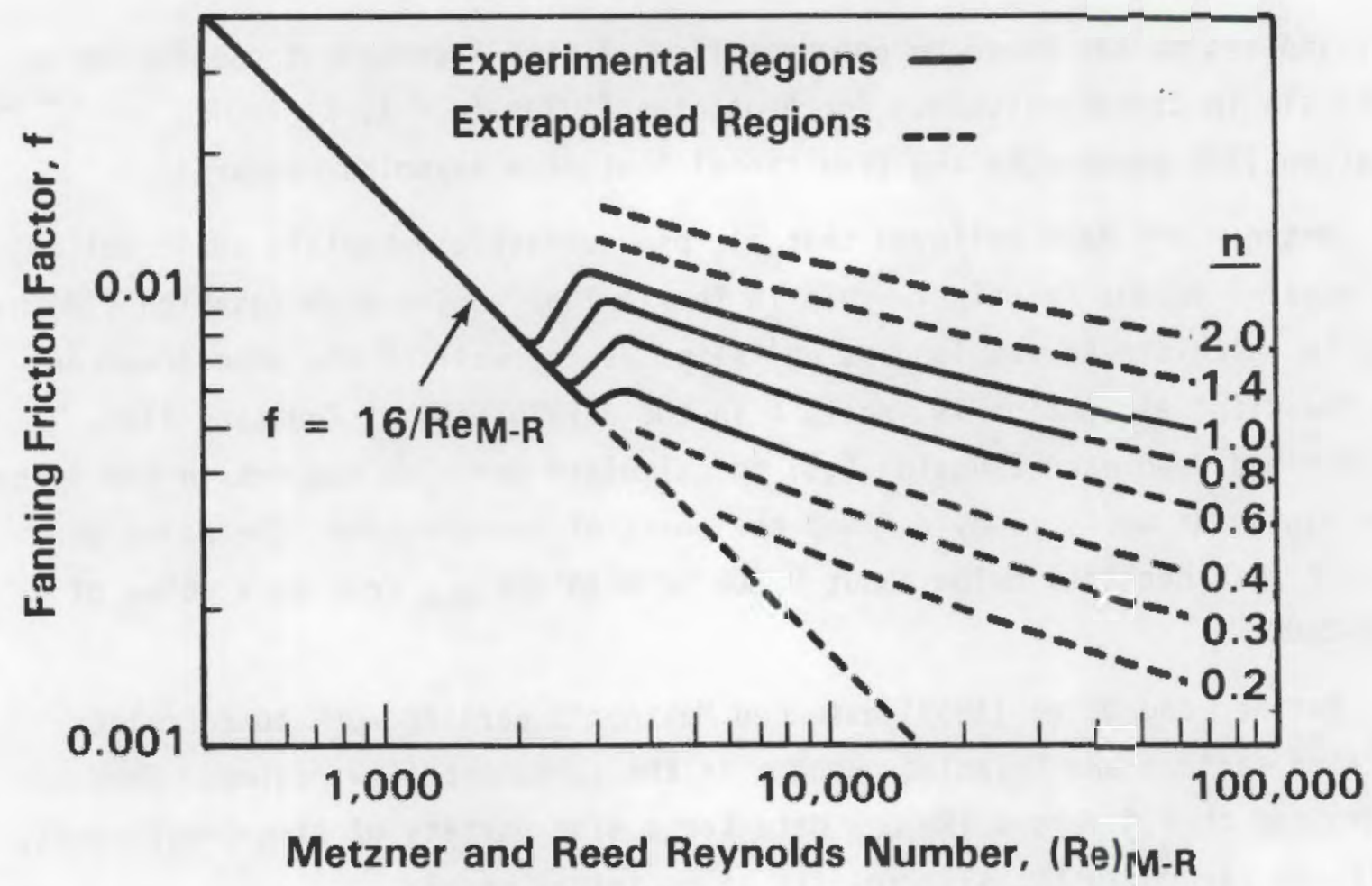

FIGURE 5.1. Metzner and Reed Friction Factor - Re Relationships

\subsection{YIELD-PSEUDOPLASTIC FLUIDS}

The relationship between shear stress and rate of shear for a yieldpseudoplastic material was defined as:

$$
\begin{gathered}
\tau=k\left(\frac{d V}{d y}\right)^{n} \text { when } \tau_{y}=0 \\
\tau=\tau_{y}+\left(\frac{d V}{d y}\right)^{n} \text { when } \tau_{y}>0
\end{gathered}
$$

The yield pseudoplastic model reduces to the Bingham plastic model when $n=1$, the pseudoplastic model when $\tau_{y}=0$, and the Newtonian model when $\tau_{y}=0$ and $n=1$. 
Theoretical design equations based on mixing length theory and Equations (20) and (21) have been developed to permit the design of pipelines for the pseudohomogeneous flow of yield-pseudoplastic fluids (Hanks 1978). The equations merge with similar equations developed for pseudoplastic fluids (Hanks and Ricks 1975, Hanks and Daldia 1971). The derivation of the equations is a complex exercise that will not be repeated here; rather, some of the concepts developed will be described.

The existence of a yield stress $\tau_{y}$ distinguishes yield-pseudoplastic fluids. The yield stress must be exceeded before flow can begin. The particle structure that creates the yield stress will affect the velocity distribution patterns developed during laminar flow. A higher shear rate is required to achieve a given velocity distribution pattern for a yield-pseudoplastic fluid than is required for a fluid without a yield stress. This additional shear rate requirement produces a higher value of the Fanning friction factor at a given laminar Re for fluids with yield stresses, and increases the value of the critical Reynolds number, $\mathrm{Re}_{\mathrm{c}}$, the Reynolds number that occurs at the transition from laminar to turbulent flow.

Hedstrom was the first investigator to account for the effects of $\tau$ on $\mathrm{Re}_{\mathrm{C}}$ (Hedstrom 1952). He identified a parameter, later known as the Hedstrom number, He, that accounts for these $\tau_{y}$ effects. The Hedstrom number is defined as:

$$
H e=\frac{D^{2} \rho}{K^{1}}\left(\frac{\tau}{K^{T}}\right)^{\frac{2-n}{n}}
$$

where: $D=$ pipe diameter, $m$

$$
\begin{aligned}
\rho & =\text { fluid density, } \mathrm{kg} / \mathrm{m}^{3} \\
\tau_{y} & =\text { yield stress, } \mathrm{Pa} \\
K^{\prime} & =\text { flow consistency index, } \mathrm{Pa} \cdot \mathrm{s} \\
n & =\text { flow behavior index. }
\end{aligned}
$$

The effects of He on $f$ and $\operatorname{Re}_{c}$ have been examined in detail by Hanks (Hanks 1978), and are depicted on Figures 5.2 and 5.3. As the value of $\mathrm{He}$ 


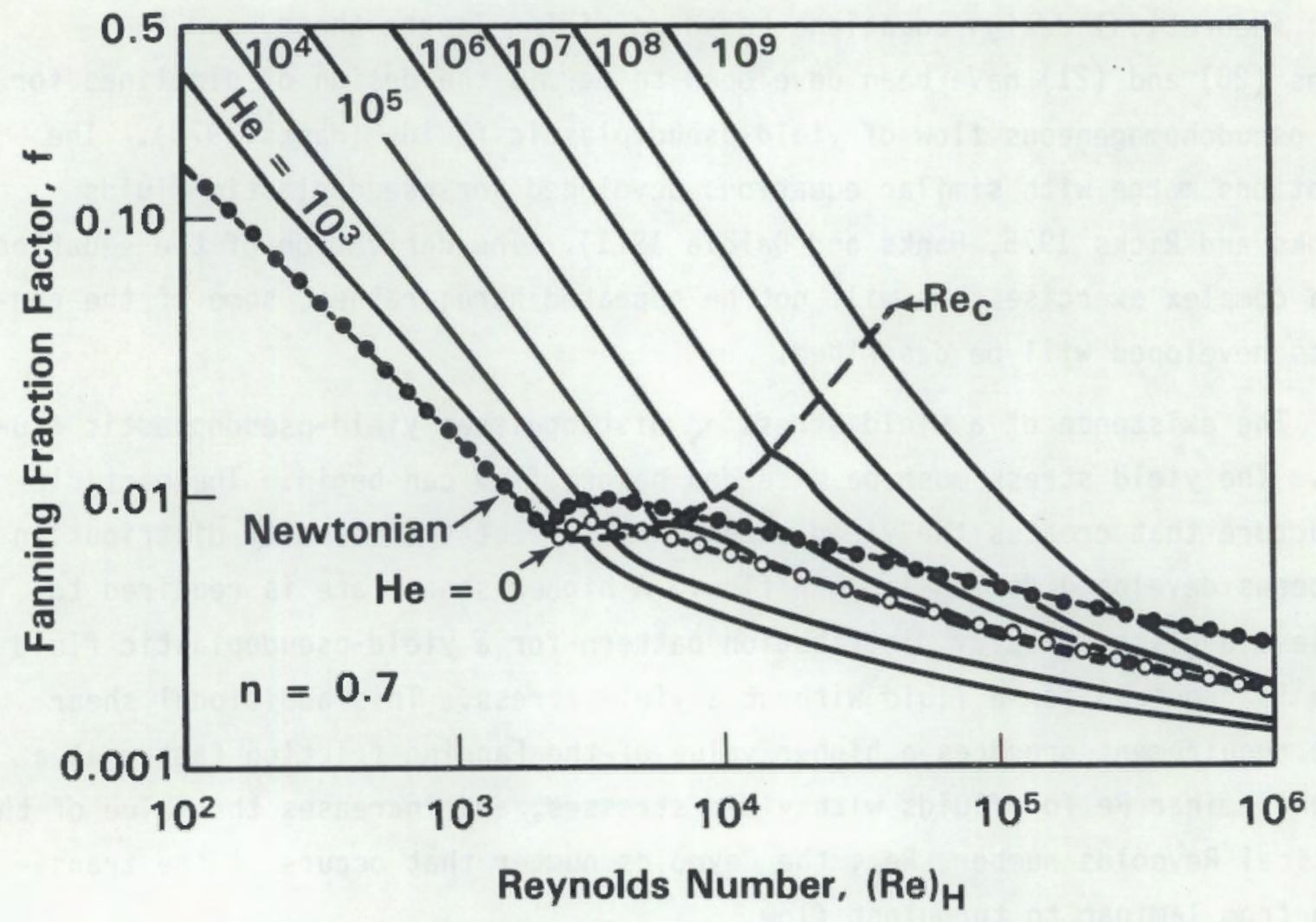

FIGURE 5.2. Yield-Pseudoplastic Design Curve - $f$ Versus $\operatorname{Re}(n=0.7)$

increases, 1) the friction factor increases substantially at a given Reynolds number and 2) the critical Reynolds number occurs at values much higher than 2100 .

The calculation procedure suggested by Hanks (1978) accounts for the effects of $\tau_{y}$ on laminar and turbulent velocity profiles and the resulting effects on calculated values of Re and $f$. An outline of these procedures is summarized on Figure 5.4. The equations referred to in Figure 5.4 are listed in Table 5.1. Nomenclature for Table 5.1 is summarized in Table 5.2. 


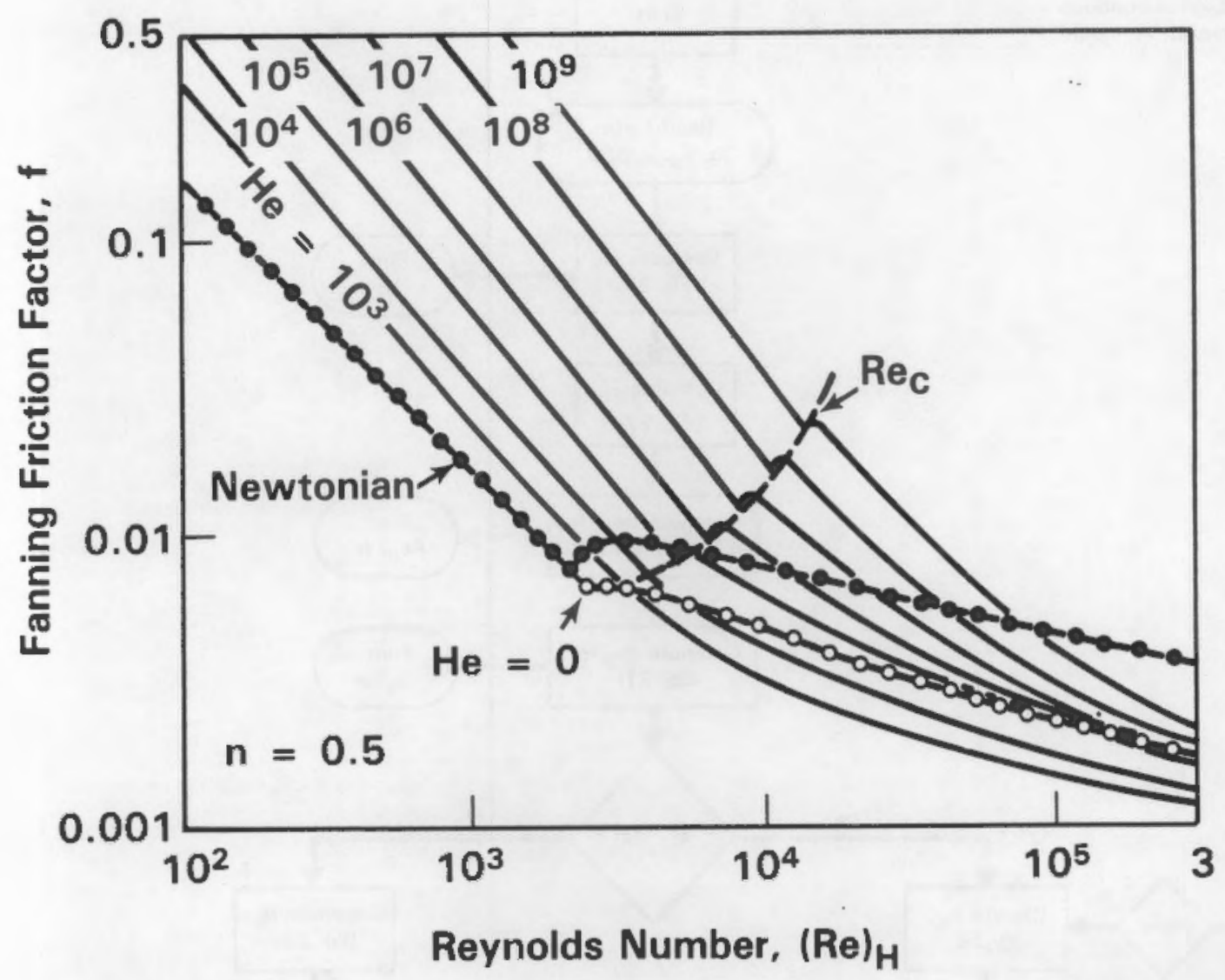

FIGURE 5.3. Yield-Pseudoplastic Design Curve - $f$ Versus $\operatorname{Re}(n=0.5)$ 
$E$ = Explicit Function

I = Implicit Function

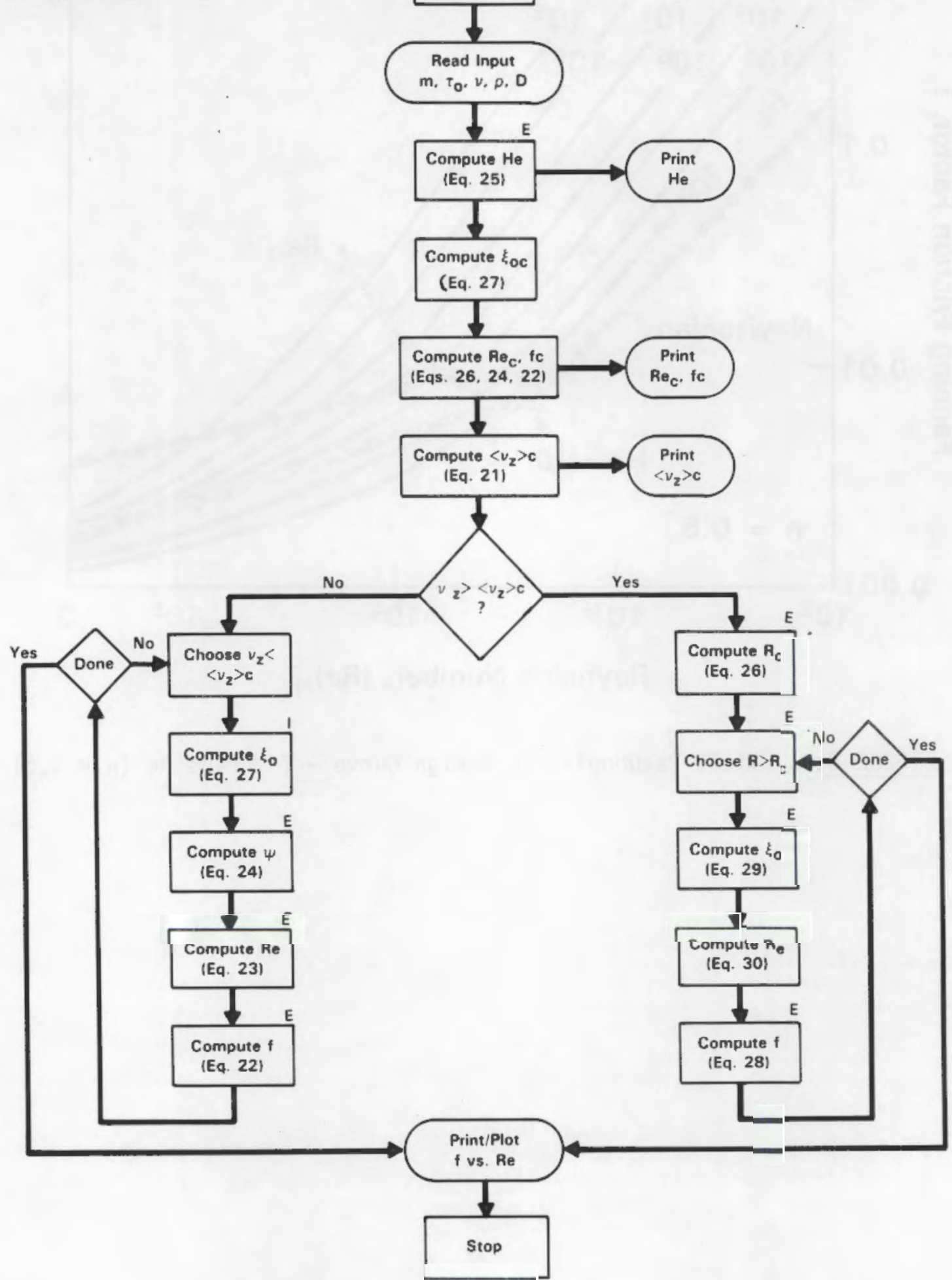

FIGURE 5.4. Hanks' Calculation Procedure for the Flow of Yield-Pseudoplastic Fluids in Pipes (Hanks 1978) 
TABLE 5.1. Hanks' Equations for the Flow of Yield-Pseudoplastic Fluids in Pipes (Hanks 1978)

$\left\langle v_{z}\right\rangle=a\left(\frac{\tau}{\eta}\right)^{1 / m}\left[\frac{m\left(1-\xi_{0}\right)^{(1+m) / m}}{\xi_{0}^{1 / m}}\right]\left[\frac{\left(1-\xi_{0}\right)^{2}}{1+3 m}+\frac{2 \xi_{0}\left(1-\xi_{0}\right)}{1+2 m}+\frac{\xi_{0}^{2}}{1+m}\right]$

$f=16 / \psi \operatorname{Re}$

$\operatorname{Re}=8\left(\frac{m}{1+3 m}\right)^{m} \frac{a^{m}\langle v\rangle^{2} \rho^{-m}}{\eta}$

$\psi=(1+3 m)^{m}\left(1-\xi_{0}\right)^{1+m}\left[\frac{\left(1-\xi_{0}\right)^{2}}{1+3 m}+\frac{2 \xi_{0}\left(1-\xi_{0}\right)}{1+2 m}+\frac{\xi_{0}}{1+m}\right]^{m}$

$H e=\frac{D^{2} \rho}{\eta}\left(\frac{\tau}{\eta}\right)(2-m) / \frac{m}{=} \frac{D^{2} \rho}{\tau_{0}}\left(\frac{\tau}{\eta}\right)^{2 / m}$

$\operatorname{Re}_{c}=\frac{6464 m}{(1+3 m)^{m}}(2+m)^{\frac{2+m}{1+m}} \frac{\left[\frac{\left(1-\xi_{o c}\right)^{2}}{1+3 m}+\frac{2 \xi_{o c}\left(1-\xi_{o c}\right)}{1+2 m}+\frac{\xi_{o c}{ }^{2}}{1+m}\right]^{2-m}}{\left(1-\xi_{o c}\right)^{m}}$

$H e=\frac{3232}{m}(2+m)^{\frac{2+m}{1+m}}\left[\frac{\xi_{o c}}{\left(1-\xi_{o c}\right)^{1+m}}\right]^{\frac{2-m}{m}}\left[\frac{1}{1-\xi_{o c}}\right]^{m}$

$R=\left(\frac{1+3 m}{m}\right)\left[\operatorname{Re}\left(\frac{f}{16}\right)^{\frac{2-m}{2}}\right]^{1 / m}$

$R e=\left(1-\xi_{0}\right)^{\frac{2-m}{m}}\left(\frac{m}{1+3 m}\right) R^{2}\left[\xi_{0}^{1} \xi^{2} \zeta\left(\xi, \xi_{0}, R\right) d \xi\right]^{2-m}$

$R^{2}=2 H e / \xi_{0}^{(2-m) / m}$ 
TABLE 5.2. Nomenclature for Table 5.1

\begin{tabular}{|c|c|c|}
\hline Symbol & Definition & Units \\
\hline a & Pipe radius & m \\
\hline D & Pipe diameter & m \\
\hline f & Fanning friction factor & -- \\
\hline $\mathrm{He}$ & Generalized Hedstrom number & -- \\
\hline m & Flow behavior index & -- \\
\hline R & Turbulence parameter & - \\
\hline $\mathrm{R}_{c}$ & Value of $R$ at laminar-turbulent transition & -- \\
\hline $\operatorname{Re}$ & Reynolds number & - \\
\hline $\operatorname{Re}_{C}$ & Laminar-turbulent transition value of $\mathrm{Re}$ & -- \\
\hline$v_{z}$ & Axial velocity component & $\mathrm{m} / \mathrm{sec}$ \\
\hline$\left\langle v_{z}\right\rangle$ & Area mean value of $v_{z}$ & $\mathrm{~m} / \mathrm{sec}$ \\
\hline$\left\langle v_{z}\right\rangle c$ & $\begin{array}{l}\text { Laminar-turbulent transition value of } \\
\left\langle v_{z}\right\rangle\end{array}$ & $\mathrm{m} / \mathrm{sec}$ \\
\hline$z$ & Axial coordinate & - \\
\hline$\eta$ & Yield-power law consistency index & $\mathrm{Pa} \cdot \mathrm{S}$ \\
\hline$\zeta$ & Dimensionless shear rate & -- \\
\hline$\xi$ & Dimensionless radial coordinate, $r / a$ & - \\
\hline$\xi_{0}$ & Dimensionless unsheared plug radius, $\tau_{0} / \tau_{W}$ & \\
\hline$\xi_{\mathrm{OC}}$ & Laminar-turbulent transition value of $\xi_{0}$ & -- \\
\hline$\rho$ & Slurry density & $\mathrm{kg} / \mathrm{m}^{3}$ \\
\hline$\tau_{0}$ & Yield stress & $\mathrm{Pa}$ \\
\hline$\tau_{w}$ & Value of $\tau_{r z}$ at $r=a$ & $\mathrm{~Pa}$ \\
\hline$\psi$ & Laminar flow function & -- \\
\hline
\end{tabular}




\subsection{DESIGN REQUIREMENTS FOR THE FULL-SCALE SYSTEM}

One goal of this rheological evaluation of NCAW was to evaluate those rheological and transport properties critical to assuring the successful handling of three concentrations of this slurry in a full-scale pump-pipe network. The purpose of this section is to scale up laboratory results to establish the process design needs of the full-scale pump-pipe network that will transport NCAW slurries from DSTs to B-Plant.

The full-scale pump-pipe network must transport NCAW slurries at velocities that prevent the deposition of solids in the transfer lines. Laboratory critical transport property estimates will be scaled up to predict full-scale performance in Section 6.1. The centrifugal pump used to transport NCAW must be sized to deliver the NCAW slurries through approximately 9100 feet of $3-i n$., Schedule 40, smooth, carbon steel pipe. The pressure drop that can be expected to occur in this pipe will be estimated in Section 6.2. Ful1-scale lineflushing requirements will be discussed in Section 6.3 .

\subsection{SCALE-UP OF LABORATORY RHEOLOGICAL DATA}

The pseudoplastic (Metzner and Reed 1955) and yield-pseudoplastic (Hanks 1978) rheological models were used to scale up laboratory data. The critical Reynolds number predicted by the pseudoplastic model is only a function of the flow behavior index, $n$ (see Figure 5.1). For instance, for an $n$ of 0.8 , the pseudoplastic model will predict an $R_{c}$ of about 2150 for any pipe diameter.

The yield-pseudoplastic model accounts for the effects of $\tau_{y}$ and pipe diameter on $\operatorname{Re}_{C}$ and provides a way to predict $\operatorname{Re}_{C}$ for various combinations of $\tau_{y}, n, K^{\prime}$, and pipe diameter. The pseudoplastic, and yield-pseudoplastic approaches to the scale-up of pump-pipe test loop data are discussed in this section. Each model has been used successfully to scale up laboratory rheological data to predict critical transport properties in pump-pipe networks (McCarthy, Chan, and Lokken 1985). 


\subsubsection{Pseudoplastic Model}

The pseudoplastic $n$ and $K^{\prime}$ parameters, the predicted $\left(R_{C}\right)_{M-R}$ values and critical pipeline velocities for NCAW and NCAW5.5 in the full-scale system are summarized in Table 6.1. The critical velocity value is based on a full-scale pipe diameter of $3 \mathrm{in}$. All of the predicted values of $\left(V_{c}\right)$ are well below the minimum design velocity in the full-scale pipe network (2.1 fps; $50 \mathrm{gpm})$.

\subsubsection{Yield-Pseudoplastic Mode1}

The yield-pseudoplastic model relies on the approach summarized in Figure 5.4. The available estimates of $\tau_{y}, n, K^{\prime}$, fluid density and pipe diameter are used to calculate the value of the Hedstrom number He. This value of He is used to define the laminar-turbulent transition value of $\tau_{y} / \tau_{w}$. The $\operatorname{Re}_{c}$ for the system can be estimated once the laminar-turbulent transition value of $\tau_{y} / \tau_{w}$ has been established. An iterative calculation procedure is required to calculate this value of $\tau_{y} / \tau_{w}$ (see Figure 5.4).

The yield-pseudoplastic rheological parameters obtained during laboratory tests were used to predict values of $\operatorname{Re}_{c}$ for NCAW1:1 in a 3-in. diameter schedule 40 carbon steel pipe. These predictions are summarized in Table 6.2. All of the predicted values of $\operatorname{Re}_{c}$ are below the design velocity of $2.1 \mathrm{fps}$ (50 gpm) for the full-scale system.

TABLE 6.1. Predictions of Full-Scale Critical Flow Properties:
Pseudoplastic Model

\begin{tabular}{|c|c|c|c|c|}
\hline \multirow[b]{2}{*}{ Property } & \multicolumn{2}{|c|}{ NCAW } & \multicolumn{2}{|c|}{ NCAW5.5 } \\
\hline & $\left(25^{\circ} \mathrm{C}\right)$ & $\left(100^{\circ} \mathrm{C}\right)$ & $\left(25^{\circ} \mathrm{C}\right)$ & $\left(100^{\circ} \mathrm{C}\right)$ \\
\hline $\mathrm{n}$ & 0.8 & 0.57 & 0.85 & 0.6 \\
\hline $\mathrm{K}^{\prime}(\mathrm{Pa}-\mathrm{sec})$ & 0.0149 & 0.0211 & 0.0126 & 0.0183 \\
\hline$\left(\operatorname{Re}_{c}\right)_{M-R}$ & 2150 & 2300 & 2150 & 2300 \\
\hline$V_{c}(f p s)$ & 0.62 & 0.5 & 0.58 & 0.5 \\
\hline$Q_{C}(g p m)$ & 13.8 & 11.5 & 13.5 & 11.5 \\
\hline
\end{tabular}

(a) Values are based on the average values of $X^{\prime}$ and $n$ obtained with three laboratory samples of NCAW and NCAW5.5. 
TABLE 6.2. Predictions of Full-Scale Criticalaflow Properties for
NCAW1:1 Yield-Pseudoplastic Model

\begin{tabular}{|c|c|c|}
\hline Property & $\left(25^{\circ} \mathrm{C}\right)$ & $\left(100^{\circ} \mathrm{C}\right)$ \\
\hline$\tau_{y}(\mathrm{~Pa})$ & 0.60 & 1.25 \\
\hline n & 0.83 & 1.15 \\
\hline$K^{\prime}(\mathrm{Pa}-\mathrm{sec})$ & 0.0123 & 0.0006 \\
\hline $\mathrm{He}$ & 136000 & 4280000 \\
\hline $\operatorname{Re}_{\mathrm{C}}$ & 6625 & 41120 \\
\hline$V_{c}(\mathrm{ft} / \mathrm{sec})$ & 1.52 & 1.20 \\
\hline$Q_{c}(\mathrm{gpm})$ & 35.1 & 27.6 \\
\hline
\end{tabular}
(a) Values are based on the average values
of $n, K^{\prime}$ and $\tau^{\prime}$ obtained with three
laboratory samples of NCAW1:1.

\subsection{PRESSURE OROP EXPECTED IN THE FULL-SCALE SYSTEM}

The pressure drop in the full-scale system can be estimated by the following equation:

$$
\Delta P=\left(\frac{4 L f}{D}\right)\left(\frac{p v^{2}}{2 g_{c}}\right)
$$

The pressure drop in the full-scale system will be a function of the equivalent length, $L$, of the system, the diameter of the transfer pipe, $D$, the velocity in the pipe, $v$, and the friction factor, $f$, developed as the fluid passes through the pipe. The friction factor is in turn a function of the physical and rheological properties of the fluid, the Reynolds number, and the roughness of the internal surface of the pipe.

The pressure drop estimates discussed in this section are all based on assumptions listed in Table 6.3. These assumptions reflect the current design parameters for the full-scale system. 
TABLE 6.3. Assumptions in Full-Scale Pressure Drop Calculations

\begin{tabular}{|c|c|c|}
\hline Item & Symbol & Value \\
\hline Equivalent length & $\mathrm{L}$ & 9100 feet \\
\hline Pipe roughness & $\varepsilon$ & smooth pipe \\
\hline Temperature & - & $25^{\circ} \mathrm{C}$ and $100^{\circ} \mathrm{C}$ \\
\hline Pipe diameter & $D$ & 3.068 inches \\
\hline Line velocities & V & $\begin{array}{l}2.17 \text { fps normal } \\
3.31 \text { fps maximum }\end{array}$ \\
\hline
\end{tabular}

\subsubsection{NCAW, NCAW5.5 and NCAW1:1 Slurries}

The relationship between $f$ and Re depends on the rheological model used to calculate Re. The pseudoplastic model was used to evaluate NCAW and NCAW5.5 at 25 and $100^{\circ} \mathrm{C}$. The yield-pseudoplastic model was used to evaluate NCAW1:1.

\subsubsection{Pseudoplastic Model}

The Reynolds number for pseudoplastic fluids is given by Equation (34):

$$
(R e)_{M-R}=\frac{D^{n} v^{2-n} \rho}{g_{C} K^{\prime} 8^{n-1}}
$$

The parameters $n$ and $K^{\prime}$ obtained during laboratory tests were used to calculate $(R e)_{M-R}$ for the normal and maximum fluid velocities indicated in Table 6.3. This value of $(R e)_{M-R}$ was used to establish the friction factor, $f$. The predicted values of pressure drop for the full-scale system are summarized in Table 6.4.

For the normal flow case, the predicted values of pressure drop for 9100 feet of $3-i n$. diameter schedule -40 pipe for NCAW and NCAW5.5 at $25^{\circ} \mathrm{C}$ is 41 psig and, for the maximum flow case, 79 psig. For NCAW and NCAW5.5 at $100^{\circ} \mathrm{C}$, the pressure drop values are $28 \mathrm{psig}$ and $56 \mathrm{psig}$ for the normal and maximum flow case, respectively. These predictions of pressure drop must be adjusted when information about the pipe roughness of the actual full-scale pipe network becomes available. 
TABLE 6.4. Prediction of Full-Scale Pressure Orop: Pseudoplastic Model(a)

\begin{tabular}{|c|c|c|c|c|}
\hline \multirow[b]{2}{*}{ Item } & \multicolumn{2}{|c|}{ NCAW } & \multicolumn{2}{|c|}{ NCAW5. 5} \\
\hline & $25^{\circ} \mathrm{C}$ & $100^{\circ} \mathrm{C}$ & $25^{\circ} \mathrm{C}$ & $100^{\circ} \mathrm{C}$ \\
\hline$n$ & 0.8 & 0.57 & 0.85 & 0.6 \\
\hline$g_{c} K^{\prime}\left(1 b_{m} / f t-s e c\right)$ & 0.0101 & 0.0142 & 0.0085 & 0.009 \\
\hline$\rho\left(1 b_{m} / \mathrm{ft}^{3}\right)$ & 79.2 & 78.6 & 81.1 & 80.5 \\
\hline$(\operatorname{Re})_{M-R^{-n o r m a l}}$ & 9,650 & 11,500 & 9,660 & 17,900 \\
\hline$(\operatorname{Re})_{M-R}$-maximum & 15,700 & 20,600 & 15,400 & 31,700 \\
\hline f-normal & 0.007 & 0.005 & 0.007 & 0.005 \\
\hline$f$-maximum & 0.006 & 0.004 & 0.006 & 0.004 \\
\hline $\begin{array}{l}\Delta P \text { normal } \\
(p s i / 1000 \mathrm{ft})\end{array}$ & 4.4 & 3.1 & 4.5 & 2.9 \\
\hline $\begin{array}{l}\Delta P \operatorname{maximum} \\
(\mathrm{ps} i / 1000 \mathrm{ft})\end{array}$ & 8.5 & 6.2 & 8.7 & 5.6 \\
\hline
\end{tabular}

(a) $\triangle P$ values are based on average values obtained with three laboratory samples
of NCAW and NCAW5.5.

\subsubsection{Yield Pseudoplastic Model}

The Reynolds number for yield-pseudoplastic fluids is calculated by the iterative procedure summarized on Figure 5.4 The parameters $n, K^{\prime}$ and $y$ obtained during laboratory and pilot-scale tests were used to calculate $(\operatorname{Re})_{H}$ for the normal and maximum fluid velocities indicated in Table 6.4. The predicted values of pressure drop for the full-scale system are summarized in Table 6.5.

For the normal flow case, the predicted value of pressure drop for 9100 feet of 3-in. diameter schedule-40 pipe for NCAW1: 1 at $25^{\circ} \mathrm{C}$ is 38 psig, and for the maximum flow case, 72 psig. For NCAW1:1 at $100^{\circ} \mathrm{C}$, the pressure drop values are $36 \mathrm{psig}$ and $60 \mathrm{psig}$ for the normal and maximum flow cases, respectively. These pressure drops are similar to those predicted for the NCAW and NCAW5. 5 slurries. These predictions must be adjusted as information about the full-scale pipe roughness becomes available. 
TABLE 6.5. Prediction of Full-Scale Pressure Drop:
Yield-Pseudoplastic Model

\begin{tabular}{|c|c|c|}
\hline \multirow{2}{*}{ Item } & \multicolumn{2}{|c|}{ NCAW $1: 1$} \\
\hline & $25^{\circ} \mathrm{C}$ & $100^{\circ} \mathrm{C}$ \\
\hline n & 0.83 & 1.15 \\
\hline$g_{c} K^{\prime}\left(1 b_{m} / f t-s e c\right)$ & 0.0083 & 0.0004 \\
\hline$\tau_{y}\left(1 b_{m} / f t-\sec ^{2}\right)$ & 0.39 & 0.84 \\
\hline$\rho\left(1 b_{m} / f t^{3}\right)$ & 73.8 & 72.2 \\
\hline$(\mathrm{Re})_{\mathrm{H}^{-n o r m a l}}$ & 9,780 & 66,200 \\
\hline$(\mathrm{Re})_{\mathrm{H}^{- \text {maximum }}}$ & 15,700 & 92,300 \\
\hline f-norma 1 & 0.0071 & 0.0069 \\
\hline$f$-maximum & 0.0060 & 0.0051 \\
\hline$\Delta \mathrm{P}$-normal $(\mathrm{psi} / 1000 \mathrm{ft})$ & 4.2 & 4.0 \\
\hline$\Delta P$-maximum (psi/1000 ft) & 7.9 & 6.6 \\
\hline
\end{tabular}

(a) $\triangle \mathrm{Ps}$ are based on average values obtained with three laboratory samples of NCAW and NCAW5.5.

\subsection{FULL-SCALE LINE-FLUSHING REQUIREMENTS}

The full-scale pump-pipe network will be subject to process upsets, which could cause NCAW slurry to remain in the transfer piping for extended periods of time. The NCAW solids will settle from the suspension during this time period. The full-scale pump must be able to resuspend settled NCAW solids and clean the pipe network after a process upset.

The "resuspendability" of a slurry will depend on the complex chemical and physical interactions that occur between the solid and liquid phases of the slurry. Several empirical relationships have been developed to account for these interactions and identify resuspension velocities. These relationships are described in Section 6.3.1.

\subsubsection{Empirical Estimates}

Resuspension has been defined as the condition in which settled particles are influenced by an accelerating fluid to become suspended by the increasing fluid turbulence until the system reaches its final steady state condition (no 
further acceleration). The phenomenon in which there is impending motion of a number of particles from a stationary bed of granular materials into a liquid medium is termed "incipient motion." Incipient motion is reached when the forces acting on the settled particles equal the forces resisting movement of the particles. Further increases in flow rate will increase particle movement until a steady state flow condition (stationary bed, moving bed, heterogeneous, pseudohomogeneous) is achieved (Kao et a1. 1978).

The degree of resuspension achieved will be a function of the pressure gradient applied to the settled solids and the steady-state fluid velocity achieved in the pipe. This relationship is described on Figure 6.1. Incipient motion is achieved at point $A$ on Figure 6.1. An additional force is required to break through particle cohesive forces and resuspend the settled solids

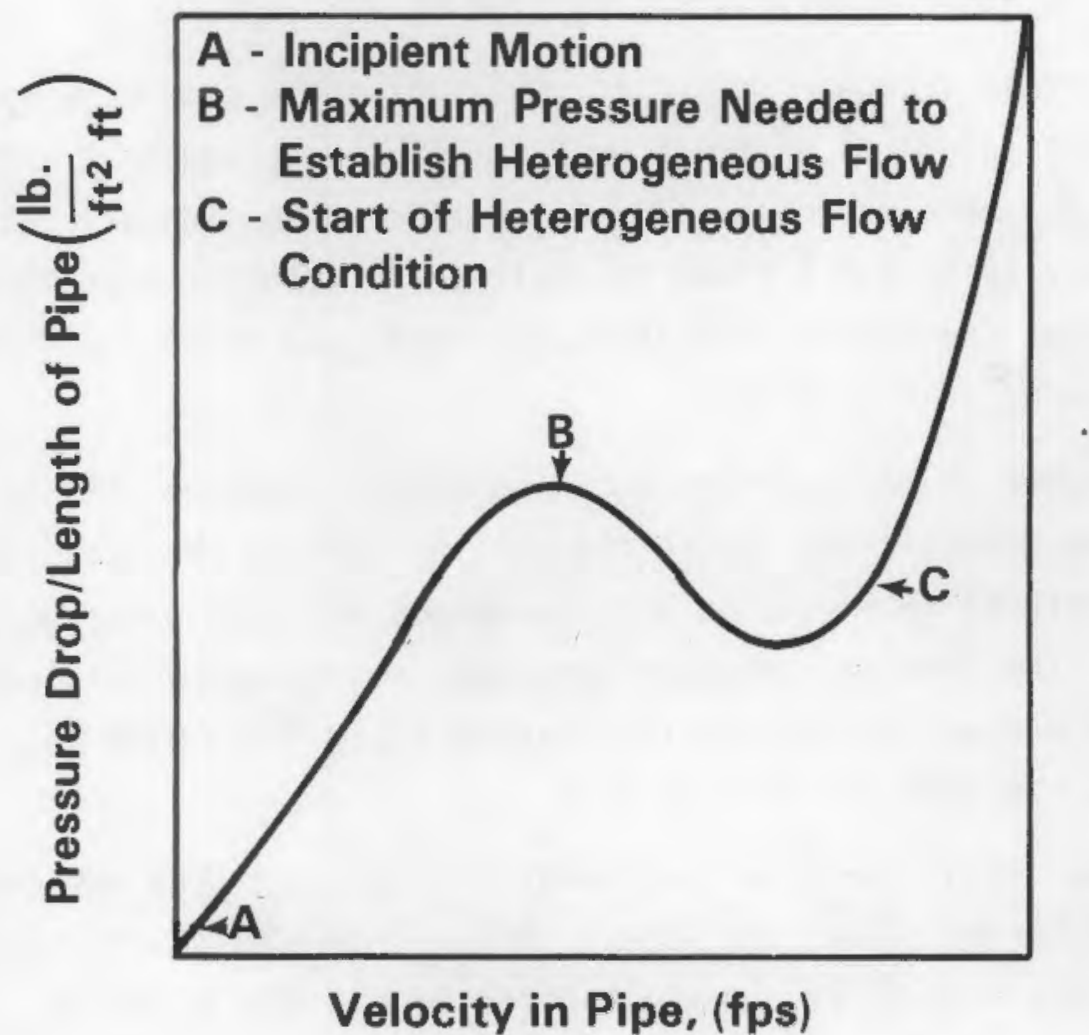

FIGURE 6.1. Effects of Pressure Applied and Fluid Velocity on the Resuspension of Settled Solids 
(point B). Once this condition is reached an increase in fluid velocity and decrease in pressure drop will occur (point C). The pressure gradient will then increase slowly with velocity until a steady-state heterogeneous or pseudohomogeneous flow condition is reached.

The critical flushing velocity must be greater than the critical deposition velocity, $V_{c d}$, indicated by point $C$ on Figure 6.1. Many empirical methods have been developed to estimate $V_{c d}$ (Wiedenoth and Kirchner 1972, Govier and Aziz 1982). These methods were developed for specific solid-liquid systems and are not generally applicable to other systems. They require a detailed knowledge of particle size distribution, particle shape and particle density that are not available for NCAW slurry. The critical deposition velocity, $V_{c d}$, will be approximately equal to the velocities associated with the critical Reynolds number discussed in Section 6.2. These velocities are smaller than the lineflushing velocities that will be utilized by Rockwell.

The current Rockwell design for the full-scale pump-pipe system specified that one pipe-volume of water be used for flushing, and that this water be delivered at a rate of $75 \mathrm{gpm}(3.3 \mathrm{fps})$. A resuspension velocity of $3.3 \mathrm{fps}$ is approximately 5, 5, and 2 times the full-scale velocities predicted as the laminar-turbulent transition velocities for NCAW, and NCAW5.5 and NCAW1:1, respectively at $25^{\circ} \mathrm{C}$.

The degree of resuspension achieved during flushing will be a function of the pressure gradient applied to the settled solids, the steady-state fluid velocity achieved in the pipe, and the amount of flush water delivered during the flush. The pressure gradient necessary to resuspend settled NCAW must be established during pilot-scale tests using a pump-pipe test loop. These tests were beyond the scope of this project.

A series of pilot-scale resuspension tests with NCRW was completed recently (McCarthy, Chan, and Lokken 1985). The NCRW slurry exhibited properties that were similar to those exhibited by the NCAW slurries. Some of these properties are summarized in Table 6.6. Table 6.6 shows that the predicted pressure drop for NCAW1: 1 is lower than for NCAW5.5 even though the viscosity of NCAW1:1 is higher. For Newtonian and non-Newtonian fluids, the pressure drop is a function of the friction factor. For Newtonian fluids, the friction 
TABLE 6.6. Comparison of NCAW and NCRW Slurry Properties at $25^{\circ} \mathrm{C}$

\begin{tabular}{|c|c|c|c|c|}
\hline Property & NCRW & NCAW & NCAW5.5 & NCAW1:1 \\
\hline Viscosity at $50 \mathrm{sec}^{-1}, \mathrm{cP}$ & 4 & 8 & 8 & 18 \\
\hline$V_{c}$-full-scale, fps & $0.3-0.4$ & $0.5-0.6$ & $0.5-0.6$ & $1.2-1.5$ \\
\hline $\begin{array}{l}\Delta \mathrm{P} \text { for } 9100 \mathrm{ft} \text {, psi } \\
\text { at } 2.1 \mathrm{fps}\end{array}$ & $31-36$ & 41 & 41 & 38 \\
\hline
\end{tabular}

factor is a function of the Reynolds number and the relative roughness of the pipe. For non-Newtonian fluids, the relationship is more complex. There is not a direct correlation between viscosity and pressure drop. Therefore, as seen in Table 6.6, the fact that NCAW1:1 has a higher viscosity than the other NCAW slurries yet a lower pressure drop is not unexpected.

During the NCRW pilot-scale tests, the pressure gradient applied during resuspension equaled about 1.3 times the normal pressure drop associated with a flow velocity of $3.3 \mathrm{fps}$. If this criterion is applied to the full-scale NCAW system, pressure drops of approximately 100, 104 and 94 psig would result during flushing of NCAW, NCAW5.5, and NCAW1:1, respectively. These predictions of pressure drop requirements during full-scale line-flushing are estimates. Actual requirements must be established during pilot-scale tests.

The pressure gradient applied, flush water velocity and amount of flush water used act singularly and in combination to resuspend slurry and to clean transfer lines. The laboratory experiments conducted were not designed to examine the way in which these factors interact during the flushing procedure. Additional pilot-scale tests will be required to define these interactions and to identify the optimal flushing design for NCAW slurries. 


\subsection{REFERENCES}

Bain, A. G. and S. T. Bonnington. 1970. The Hydraulic Transport of Solids by Pipeline, Pergamon Press, New York.

Bauer, W. H. and E. A. Collins. 1967. "Thixotropy and Dilatancy." Rheology: Theory and Applications, Volume 4. Chapter 8, Academic Press.

Govier, G. W. and K. Aziz. 1982. The Flow of Complex Mixtures in Pipes, Van Nostrand Reinhold Company.

Govier, G. W., Shook, C. A., and E. 0. Lilge. 1957. "The Rheological Properties of Water Suspensions of Finely Subdivided Magnetite, Galena and Ferrosilicon," Trans. Can. Inst. Mining Met., 60, 147.

Hank, R. W.,. 1978. "Low Reynolds Number Turbulent Pipeline Flow of Pseudohomogeneous Slurries", presented at 5th Int ' 1 Conf. on Hydraulic Transport of Solids in Pipes, Hanover, Germany, BHRA Fluid Engineering, Bedford, England.

Hanks, R. W. and B. H. Dadia. 1971. "Theoretical Analysis of the Turbulent Flow of Non-Newtonian Slurries in Pipes," A.I.ChE. Journal, 17, 3, 554.

Hanks, R. W. and B. L. Ricks. 1975. "Transitional and Turbulent Pipeflow of Pseudoplastic Fluids," J. Hydronautics, 9, 1, 39.

Hanks, R. W. 1979. "The Not So Generalized Reynolds Number," Presented at Fourth International Conference on Slurry Transportation, Las Vegas, Nevada (March 1979), Slurry Transport Association, Washington, D.C.

Hanks, R. W. and D. G. Sloan. 1981. "A Rheology-Based Correlation for Minimum Deposition Velocities," Proc. 6th International Technical Conference on Slurry Transportation, Las Vegas, Nevada.

Herschel, W. H. and R. Bulkley. 1926. "Measurement of Consistency as Applied to Rubber-Benzene Solutions," Proc. ASTM, 26, 621.

Hedstrom, B. 0. A. 1952. "Flow of Plastic Materials in Pipes," I\&EC, 44, 3, 651.

Jansky, M. T. and C. M. Kronva11. 1982. "Direct Neutralization of PUREX Current Acid Waste (CAW/ZAW)." Internal Letter 65453-82-032. Rockwell International.

Jobling, A. and J. E. Roberts. 1959. "Some Observations on Dilatancy and Thixotropy" from Rheology of Dispersed Systems, edited by C. C. Mill, Pergammon Press. 
Kao, D. J. et al. 1978. Sediment Resuspension in Slurry Pipelines, IMMR36RRR3-78. Institute for Mining and Materials Research, Lexington, Kentucky.

Kirch, N. W. 1984. "Integrated Aging Waste Tank Processing Flowsheet," PFD-T-200-0005.

Lazarus, J. H. 1980. "Rheological Characterization for Optimizing Specific Power Consumption of a Phosphate Ore Pipeline," presented at 7th Int'1 Conf. on the Hydraulic Transport of Solids in Pipes, Sendai, Japan.

McCarthy, D.,M. K. C. Chan, and R. 0. Lokken. 1985. Rheological Evaluation of Pretreated Cladding Removal Waste, Pacific Northwest Laboratory, Richland, Washington, PNL-5589.

Metzner and Dodge 1959. "Turbulent Flow of Non-Newtonian Systems," AIChE Journa1, $5,2,189$.

Metzner, A. B. and J. C. Reed. 1955. "Flow of Non-Newtonian FluidsCorrelation of the Laminar, Transition, and Turbulent Flow Regions," A.I.ChE. Journa 1, 1, 4, 434.

Metzner, A. B. and M. Whitlock. 1958. Trans. Soc. Rheology, 2, 239.

Newitt, D. M., Richardson, J. F., Abbott, M., and R. B. Turtle. 1955. "Hydraulic Conveying of Solids in Horizontal Pipes." Trans. Inst. Chem. Eng., 33, 2, 93.

Skelland, A. H. P. 1967. Non-Newtonian Flow and Heat Transfer, John Wiley \& Sons, Inc., New York.

Wiedenroth, W., Dr. Ing, and M. Kirchner. 1972. "A Summary and Comparison of Known Calculations of Critical Velocity of Solid-Water Mixtures and Some Aspects of the Optimisation of Pipelines." In: Proceedings of the Second International Conference on the Hydraulic Transport of Solids in Pipes, Paper El, University of Warwick, Bedford, England. 


\section{DISTRIBUTION}

No. of

Copies

OFFSITE

30 DOE Technical Information Center

West Valley Nuclear Services Company

P.0. Box 191

West Valley, NY 14171

ATTN: C. C. Chapman

2 DOE Office of Terminal Waste

Disposal \& Remedial Action Washington, DC 20545

ATTN: J. A. Coleman

T. W. McIntosh

3 DOE Office of Defense Waste

\& Transportation Management Washington, DC 20545

ATTN: J. E. Lytle

R. K. Hevsser

T. B. Hindman

3 E. I. du Pont de Nemours \& Company, Inc.

Savannah River Laboratory

Aiken, SC 2980B

ATTN: I. D. Goren

D. M. Grimm

B. A. Hamm

\section{ONSITE}

6 DOE Richland Operations Office
C. E. Colantes
C. R. DeLannoy
M. J. Plahuta
M. W. Shupe
J. J. Sutey
J. D. White

No. of

Copies

25 Rockwell Hanford Operations

J. M. Allison

J. N. Appel

W. B. Barton

L. C. Brown

R. C. Brown

B. D. Bullough

K. G. Carothers

A. J. Diliberto

G. L. Dunford

W. R. Dworzak

M. W. Gibson

J. M. Henderson

N. W. Kirch

J. H. Lawler

D. W. Lindsey

L. A. Mihalik

D. E. Mitchell

K. E. Plummer

D. A. Reynolds

L. M. Sasaki

L. C. Stegan

D. M. Tulberg

R. E. Van der Cook

R. N. Wagner

R. D. Wojtasek

45 Pacific Northwest Laboratory

H. T. Blair

W. F. Bonner

M. R. Elmore

C. L. Fow (20)

M. S. Hanson

W. 0. Heath

D. E. Knowlton

D. E. Larson

J. M. Latkovich

R. C. Liikala

R. 0. Lokken

D. MeCarthy

A. H. McMakin

D. H. Mitchell

M. E. Peterson 
No. of

Copies

P. A. Scott

J. L. Straalsund

G. T. Thornton
No. of

Copies

R. L. Treat

Technical Information (5)

Publishing Coordination(2) 